\title{
Experimental exergy and energy analysis of a novel high- temperature heat pump with scroll compressor for waste heat recovery
}

\author{
Carlos Mateu-Royo ${ }^{\mathrm{a}^{*}}$, Joaquín Navarro-Esbría ${ }^{\mathrm{a}}$, Adrián Mota-Babilonia ${ }^{\mathrm{a}}$, Francisco Molés ${ }^{\mathrm{a}, \mathrm{b}}$ \\ Marta Amat-Albuixech ${ }^{\mathrm{a}}$ \\ aISTENER Research Group, Department of Mechanical Engineering and Construction, \\ Universitat Jaume I, Campus de Riu Sec s/n, E12071 Castelló de la Plana, Spain \\ bexpander Tech S.L. (Rank) 12600 La Vall d'Uixó, Spain
}

N.B.: This is the PREPRINT (submitted) version of this article. The final, published version of the article can be found at: https://www.sciencedirect.com/science/article/pii/S030626191931178X.

\author{
And it can be free downloaded until September 03, 2019 at: \\ https://authors.elsevier.com/a/1ZOiD_6zgtIdSg
}

\begin{abstract}
The industrial sector demands novel sustainable energy systems to advance in its decarbonisation and meet the targets of the Paris Agreement for the climate change mitigation. High-Temperature Heat Pumps (HTHPs) are being investigated as a feasible energy conversion technology alternative to traditional fossil fuel boilers. This paper presents the first experimental results of an HTHP prototype equipped with a modified scroll compressor and internal heat exchanger (IHX). The elements of the main and secondary circuits are presented, as well as the test methodology and heat balances are exposed. The tests have been performed using HFC-245fa at heat source temperatures between 60 and $80{ }^{\circ} \mathrm{C}$, and heat sink temperatures between 90 and $140{ }^{\circ} \mathrm{C}$. The heating capacity and coefficient of performance (COP) varied between 10.9 and $17.5 \mathrm{~kW}$ and between 2.23 and 3.41, respectively. An exergetic analysis indicated that the expansion valve was the component with the worst second law efficiency and the compressor presented the highest potential improvement over the other cycle components. A computational analysis of low global warming potential (GWP) refrigerant alternatives was carried out, which confirmed the benefits of using an internal heat exchanger (IHX) and the good performances of the low-GWP refrigerants: HCFO-1224yd(Z), HCFO-1233zd(E), and HFO-1336mzz(Z). Finally, we proved that the proposed system can save up to $57 \%$ of the equivalent $\mathrm{CO}_{2}$ emissions of a natural gas boiler. This paper provides a reference for the high-temperature heat pump recovery of the lowgrade waste heat from industrial energy processes.
\end{abstract}

Keywords: HTHP; liquid-to-suction heat exchanger; energy efficiency; vapour compression; prototype

Nomenclature
\begin{tabular}{|ll|}
\hline COP & coefficient of performance $(-)$ \\
$\dot{E} x$ & rate of exergy $(\mathrm{kW})$ \\
$e x$ & specific exergy $\left(\mathrm{kJ} \mathrm{kg}^{-1}\right)$ \\
$h$ & specific enthalpy $\left(\mathrm{kJ} \mathrm{kg}^{-1}\right)$ \\
$\dot{m}$ & refrigerant mass flow rate $\left(\mathrm{kg} \mathrm{s}^{-1}\right)$ \\
$P$ & pressure $(\mathrm{MPa})$ \\
$m$ & total refrigerant charge of the system $(\mathrm{kg})$ \\
\hline
\end{tabular}

\footnotetext{
* Corresponding author: Carlos Mateu-Royo

Tel: +34964728134

Email: mateuc@uji.es
} 


\begin{tabular}{|ll|}
\hline$\dot{Q}$ & heat transfer rate $(\mathrm{kW})$ \\
$T$ & temperature $\left({ }^{\circ} \mathrm{C}\right)$ \\
$\dot{V}$ & volumetric flow rate $\left(\mathrm{m}^{3} \mathrm{~s}^{-1}\right)$ \\
$\dot{W}$ & electric power consumption $(\mathrm{kW})$ \\
VHC & volumetric heating capacity $\left(\mathrm{kJ} \mathrm{m}{ }^{-3}\right)$ \\
$\mathrm{E}_{\mathrm{a}}$ & annual energy consumption $(\mathrm{kWh})$ \\
$\mathrm{L}$ & annual refrigerant leakage rate $\left(\mathrm{kg} \mathrm{year}^{-1}\right)$ \\
$\mathrm{RI}$ & relative irreversibility $(-)$ \\
$\mathrm{s}$ & specific entropy $\left(\mathrm{kJ} \mathrm{kg}^{-1} \mathrm{~K}^{-1}\right)$ \\
& \\
Greek symbols & \\
$\psi$ & exergy efficiency $(-)$ \\
$\varepsilon$ & effectiveness $(-)$ \\
$\eta$ & efficiency $(-)$ \\
$\Delta$ & variation \\
& \\
Subscripts & \\
0 & environment reference $($ dead state $)$ \\
c & compressor \\
cond & condensation \\
crit & critical \\
em & electromechanical \\
evap & evaporation \\
ev & expansion valve \\
in & inlet \\
is & isentropic \\
$\mathrm{k}$ & condenser \\
o & evaporator \\
sink & heat sink \\
source & heat source \\
vol & volumetric \\
Abbreviations & \\
GWP & global warming potential \\
HFC & hydrofluorocarbon \\
HFO & hydrofluoroolefin \\
HCFO & hydrochlorofluoroolefin \\
HTHP & high-temperature heat pump \\
IHX & internal heat exchanger \\
TEWI & total equivalent warming impact \\
\hline
\end{tabular}

\section{Introduction}

Heat pumps are an innovative technology that can substitute fossil fuels boilers and contribute to improving the energy efficiency and decarbonisation of the energy-intensive industry sector. However, their main drawbacks are the associated high initial costs and the lack of technology maturity in industrial applications [1]. Bataille et al. [2] indicated industrial heat pumps as a possible technology to aid compliance with the Paris Agreement and therefore, limit the increase in the global mean surface temperature to below $2{ }^{\circ} \mathrm{C}$ above pre-industrial levels. Meyers et al. [3] proved that a larger number of operating hours of this technology can be a promising solution for lowering carbon industrial processes heat waste.

According to the Fifth Assessment Report (AR5) of the Intergovernmental Panel on Climate Change (IPCC), the carbon energy industry is critical for the climate change mitigation because 
their greenhouse gas (GHG) emissions have doubled between 1970 and 2010 [4]. From an analysis of the industrial energy demand, it can be observed that most of the consumption comes from thermal processes at temperatures above $100{ }^{\circ} \mathrm{C}$. These are mainly performed through the combustion of fossil fuels with uncertain acquisition prices and serious environmental impacts, such as climate change. Moreover, a significant fraction (around 2.8\%) of the industrial energy consumption is rejected as low-grade waste heat below $100{ }^{\circ} \mathrm{C}$ [5]. Therefore, recovering the industrial waste heat below $100{ }^{\circ} \mathrm{C}$ and upgrading it into useful heat for the industrial thermal processes (above $100^{\circ} \mathrm{C}$ ) [6] by means of energy efficient technologies would increase the energy efficiency and reduce the carbon emissions of the industrial sector, which as being one of the three main energy consuming sectors [7]. An option can be the use of vapour compression systems, which can be integrated into different industrial and district heating processes due to the flexibility offered in terms of the wide range of operating temperatures and heating capacities.

The need to analyse the heat pump technology in the industrial sector led Arpagaus et al. [8] to perform a comprehensive review of the heat pumps with heat sink temperatures up to $160^{\circ} \mathrm{C}$, also named high-temperature heat pumps (HTHPs). They showed that the HTHPs with higher heat sink temperatures were mainly developed in research projects and their coefficient of performance (COP) can vary from 2.2 to 6.5 (70 to $30 \mathrm{~K}$ temperature lift, respectively). The working fluid selected for heat pumps determines the maximum performance obtained at certain heat sink temperatures. While at lower temperatures, traditional refrigerants such as HFC-134a, HFC-32, and HC-290 can be used in the industry [9], for high-temperature applications other fluids must be considered [10]. Moreover, for higher heat sink temperatures and temperature lifts, the COP can be improved using advanced configurations, different from the basic cycle [11].

Therefore, current research and development of HTHPs aims at covering higher heat sink temperatures with suitable working fluids and energy efficient configurations. The development status of HTHPs configurations is still mostly limited to theoretical analysis, such as those performed by Cao et al, and Mateu-Royo et al. [11,12], which considered an external heat exchanger in one and two stages, or those performed by Mota-Babiloni et al. and Yang et al. $[13,14]$, which considered HTHP cascades. Moreover, an intensive theoretical study was performed on the energy performance benefits provided by the use of zeotropic mixtures $[15,16]$.

Experimental studies are being performed using HTHP prototypes that use different technologies and working fluids in basic cycle configurations. Bamigbetan et al. [17] studied HTHPs, with an internal heat exchanger (IHX) and receiver, to delivery heat at $115^{\circ} \mathrm{C}$ (usable in industrial processes for drying and pasteurization, among others) using HC-600. They modified a 48.82 $\mathrm{m}^{3} \mathrm{hr}^{-1}$ piston compressor lubricated by $2.5 \mathrm{~kg}$ of synthetic oil and tested frequencies from 30 to $50 \mathrm{~Hz}$. The average total and isentropic compressor efficiencies were 74 and 83\%, respectively. Chamoun et al. [18] used a twin-screw water HTHP equipped with a plate condenser, an electrical expansion valve, a flash tank, and a falling film evaporator. The compression ratio and rotation speed of the compressor were 4.5 and $5000 \mathrm{rpm}$, respectively. Bobelin et al. [19] constructed an HTHP with scroll compressors, a brazed-plate heat evaporator, condenser and sub-cooler, and an electronic expansion valve to supply heat up to $125^{\circ} \mathrm{C}$ with a developmental mixture fluid. For evaporating and condensing at temperatures of 50 and $100{ }^{\circ} \mathrm{C}$, respectively, the COP was 4.48. Meroni et al. [20] validated a centrifugal compressor model with air, R-134a, and carbon dioxide, and developed a coupled optimization with a heat pump system to supply steam at $150{ }^{\circ} \mathrm{C}$. A closed-loop with cyclopentane resulted in a COP of 4.74 .

A group of researchers have tested several refrigerants mixtures prototypes in different HTHP systems. Ma et al. [21] tested the near-azeotropic mixture BY-4 in an HTHP composed by parallel scroll compressors $(23.6 \mathrm{~kW}$ power), water-cooling condenser, dry-expansion shell, tube evaporator, and electronic expansion valve. The maximum heat capacity was $122.11 \mathrm{~kW}$ with a high COP of 3.61 and the highest heat output temperature was $110{ }^{\circ} \mathrm{C}$. Zhang et al. [22] tested 
the binary near-azeotropic mixture BY-5 in an $8 \mathrm{HP}$ scroll compressor. At the heat sink temperature of $130^{\circ} \mathrm{C}$, the corresponding COP was 2.57. Yu et al. [23] reached a COP of 4 with heat source and heat sink temperatures of 75 and $120^{\circ} \mathrm{C}$, respectively, using the mixture MF-1 with semi-hermetic screw compressors, full-liquid tube-shell condenser, dry-type tube-shell evaporator, and electronic expansion valve. With a $14.5 \mathrm{~kW}$ scroll compressor, Deng et al. [24] used the NBY-1 prototype refrigerant to reach a COP of 2.74 at heat sink temperature of $130{ }^{\circ} \mathrm{C}$ and temperature lift of $50^{\circ} \mathrm{C}$. Finally, Arpagaus et al. [25] developed a prototype using HCFO$1233 \mathrm{zd}(\mathrm{E})$ as the working fluid that reached a heat generation temperature of $151^{\circ} \mathrm{C}$ with a COP of 1.1 .

Based on the above discussed literature review, it can be seen that the HTHP technology is at an early stage. Thus, the purpose of this paper is to present the first experimental results of a novel HTHP with scroll compressor for low-grade waste heat recovery. The prototype is designed to test low synthetic GWP refrigerants and reach heat sink temperatures of $140{ }^{\circ} \mathrm{C}$. Nevertheless, the first experimental results are obtained using HFC-245fa as working fluid in order to establish the reference for future alternative refrigerant drop-in replacements. The rest of this paper is organised as follows. Section 2 describes the experimental setup of the HTHP prototype and presents the measurement installation. Section 3 introduces the experimental procedures and conditions along with the presentation of the uncertainty analysis and validation data. Section 4 presents the experimental results through detailed energy and exergy analysis. Moreover, computational analysis results of low-GWP refrigerant alternatives are provided along with the environmental evaluation of the HTHP integration as a waste heat recovery system in combined heat and power (CHP) installations. Finally, the last section contains the relevant conclusions. The results of this study may provide guidelines for the further design and development of HTHPs for low-grade waste heat recovery, especially in the industrial sector.

\section{Experimental setup}

A schematic representation of the proposed HTHP prototype is shown in Fig. 1, which contains the different circuits of the complete system, and their main components, sensors, and configurations. Fig. 2 shows photo of the experimental prototype, which was built at the ISTENER laboratories of the Universitat Jaume I, Spain. The test bench is composed of the main vapour compression circuit, and two closed secondary circuits, one for the heat source and one that acts as a heat sink along with a water cooler closed circuit. The heat source circuit simulates the potential low-grade waste heat available from industrial processes and, the heat sink simulates the high-temperature consumptions.

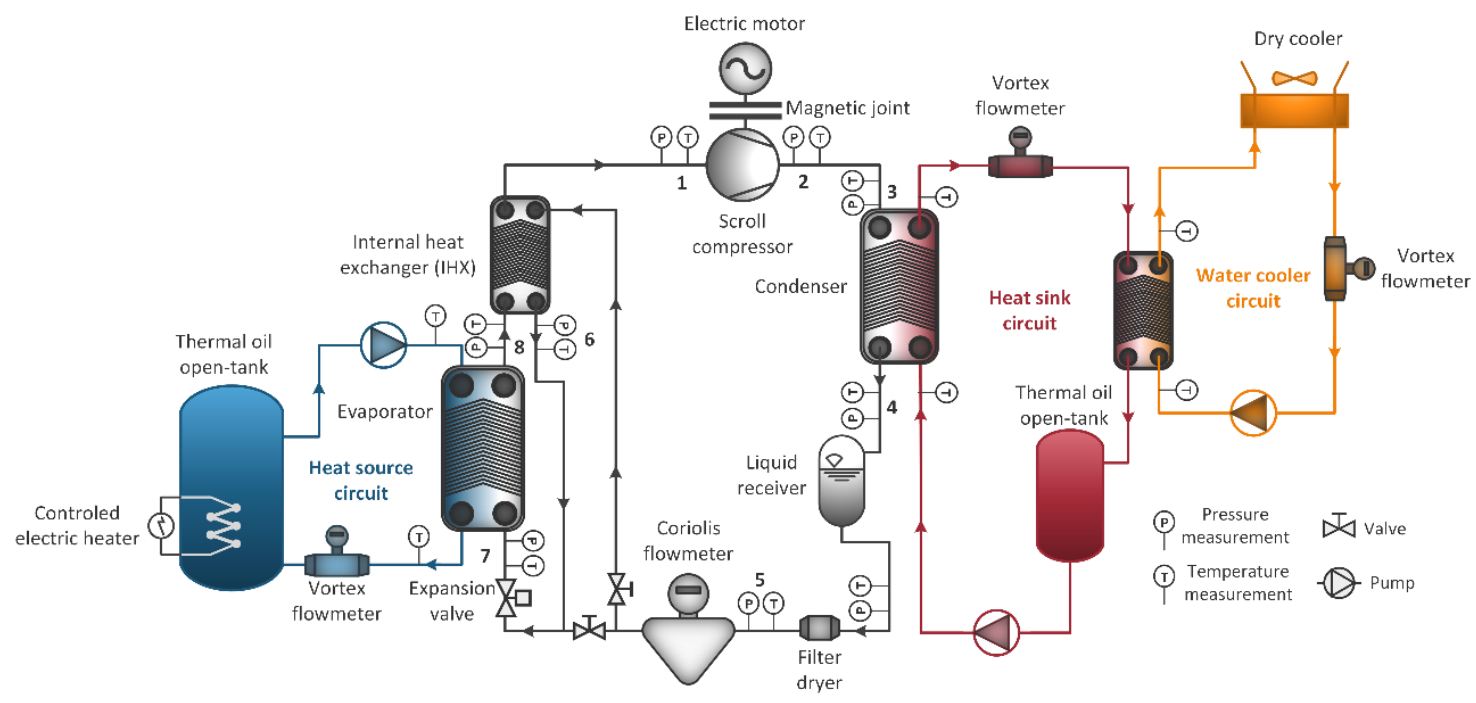


Fig. 1. Schematic diagram of the experimental test bench

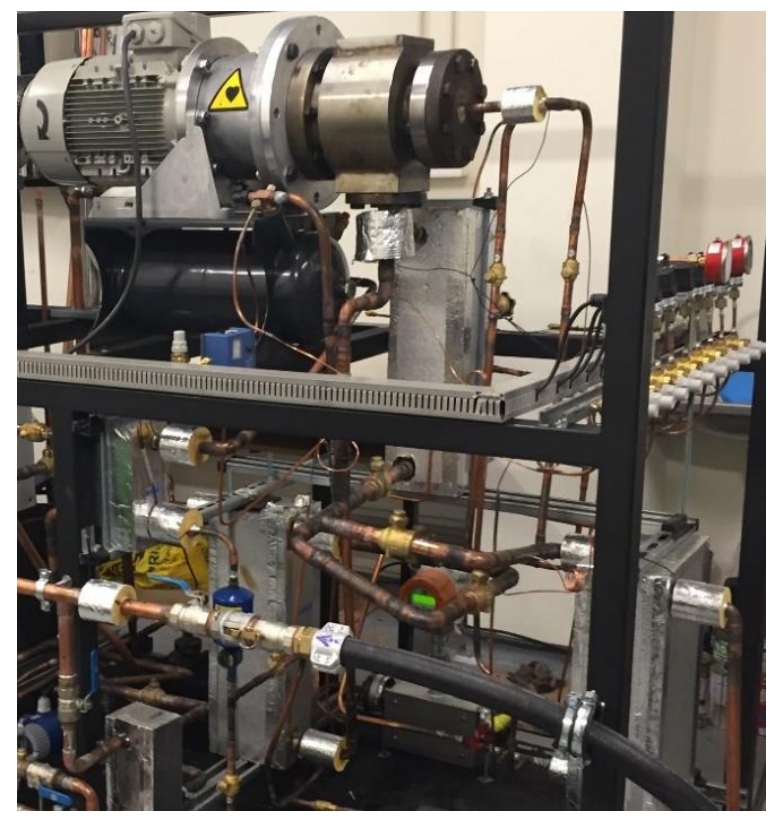

(a)

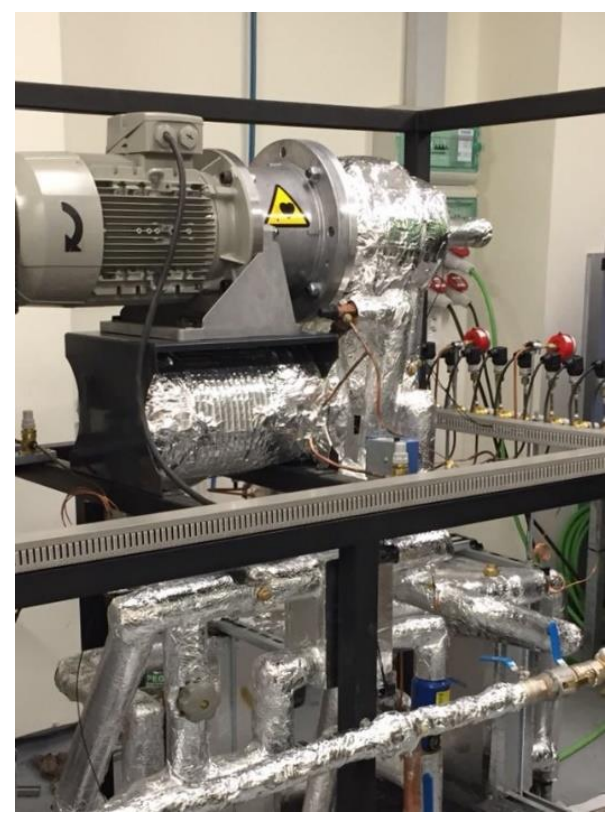

(b)

Fig. 2. Photo of the experimental prototype (ISTENER, Universitat Jaume I, Spain). (a) Startup test without thermal insulation and (b) experimental campaign once thermally insulated.

The vapour compression heat pump circuit consists of a scroll open-type compressor modified by Expander Tech S.L. with a variable-speed electric motor of $7.5 \mathrm{~kW}$ nominal power and displacement of $121.1 \mathrm{~cm}^{3}$ per revolution $(2900 \mathrm{rpm}$ at $230 \mathrm{~V}$ and $50 \mathrm{~Hz})$, magnetically coupled to each other. The compressor was modified with internal adjustments and magnetic coupling in order to ensure the operation at high-temperatures and proper lubrication. The polyester oil with a viscosity of $40 \mathrm{~mm}^{2} \mathrm{~s}^{-1}$ (at $60{ }^{\circ} \mathrm{C}$ ) is used to ensure the required compressor lubrication at high operating temperatures. All the heat exchangers (condenser, evaporator and IHX) are brazed plate type. A liquid receiver, installed after the condenser, is used to ensure the absence of bubbles before the expansion process. A manual expansion valve is installed to control the correct superheating degree owing to the lack of thermostatic models for high-temperature vapour compression applications.

The secondary circuits are used to set the targeted evaporation and condensation temperatures. The heat sink circuit uses thermal oil as the secondary fluid and is cooled by a closed-type cooling system, which allows the control of the thermal oil temperature. The volumetric flow rate can be adjusted through the variable-speed pump. The water-cooling system is composed of a PID controlled dry cooler that ensures the temperature stability of the heat sink circuit. The heat source circuit that simulates the waste heat demand also regulates the secondary thermal oil temperature through a set of immersed PID controlled electrical resistances.

The thermodynamic states of the refrigerant are obtained with the pressure and temperature measurements (obtained with thermocouples, calibrated in our laboratory using certified references, and pressure transducers) in the locations specified in Fig.1. The refrigerant mass flow rate is measured by a Coriolis mass flow meter located at the liquid line and the compressor electricity consumption is measured using a digital wattmeter. In the secondary circuits, the temperatures and volumetric flow rate are measured. Table 1 shows the characteristics of the sensors and their uncertainty. Finally, the thermodynamic properties are calculated using the REFPROP 10.0 [26]. 
Table 1: Summary of measurement sensors and uncertainties.

\begin{tabular}{|c|c|c|}
\hline Measured parameters & Sensor & Uncertainty \\
\hline Temperatures & J-type thermocouples & $\pm 0.3 \mathrm{~K}$ \\
\hline Pressures & Piezoelectric pressure transducers & $\pm 0.04 \%$ of reading \\
\hline Refrigerant mass flow rate & Coriolis mass flow meter & $\pm 0.17 \%$ of reading \\
\hline Heat source volumetric flow rate & Vortex flow meter & $\pm 0.5 \%$ of reading \\
\hline Heat sink volumetric flow rate & Vortex flow meter & $\pm 0.028 \mathrm{~m}^{3} \mathrm{~h}^{-1}$ \\
\hline Compressor power consumption & Digital wattmeter & $\pm 1.55 \%$ \\
\hline
\end{tabular}

\section{Methodology}

\subsection{Test conditions}

The test operating conditions for the experimental start-up of the HTHP system are described in Table 2. The superheating degree at the evaporator provided by IHX results in $35 \mathrm{~K}$. This value is obtained by passing a whole refrigerant mass flow rate thought the IHX. Nevertheless, the superheating degree should be control in other operating points or using different refrigerants to avoid exceeding the maximum discharge temperature.

Table 2: Operating conditions in the start-up experimental test.

\begin{tabular}{|c|c|}
\hline Controlled parameters & Values \\
\hline Heat sink outlet temperature & $90-140{ }^{\circ} \mathrm{C}$ \\
\hline Heat source inlet temperature & $60-80{ }^{\circ} \mathrm{C}$ \\
\hline Superheating degree (SH) with IHX & $35 \mathrm{~K}$ \\
\hline Compressor drive frequency & $50 \mathrm{~Hz}$ \\
\hline
\end{tabular}

The process followed for the selection of a steady state test consists in measuring for a time period of $40 \mathrm{~min}$, with a sample period of one second, in which the condensing and evaporating pressure are within an interval of $3.5 \mathrm{kPa}$. During every steady-state test, all the temperatures are within a deviation of $\pm 0.25 \mathrm{~K}$ and the refrigerant mass flow rate is within $\pm 0.0007 \mathrm{~kg} \cdot \mathrm{s}^{-1}$. Once the steadystate operation is achieved (with 2400 direct measurements), the data is processed with an algorithm in order to find the most suitable steady-state period (highest precision and accuracy) of 10 minutes (600 direct measurements). Fig. 3 shows the fluctuation and mean value for the evaporating and condensing pressures, the heat sink outlet temperature, and the refrigerant mass flow rate.

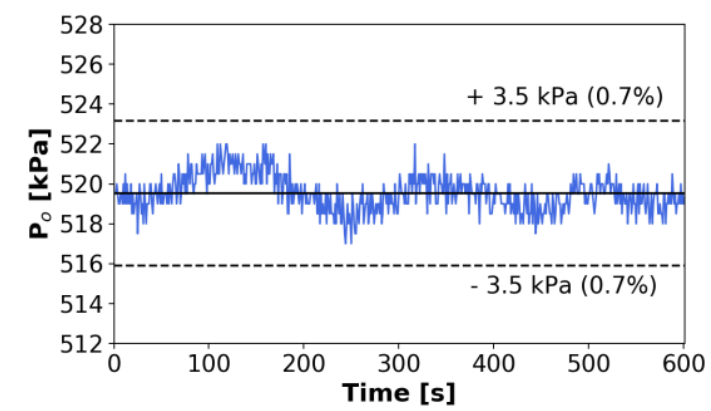

(a)

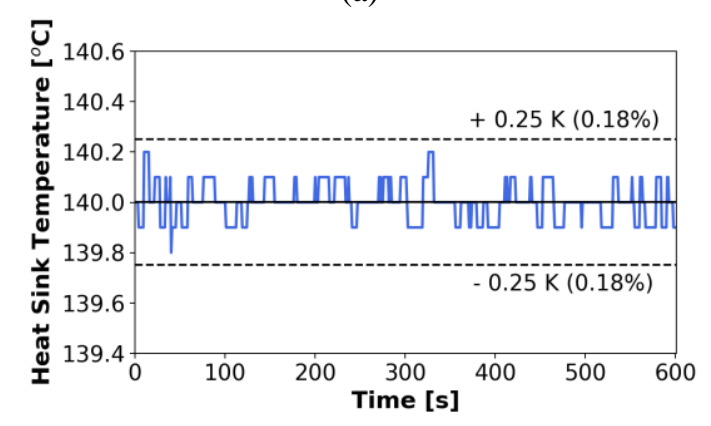

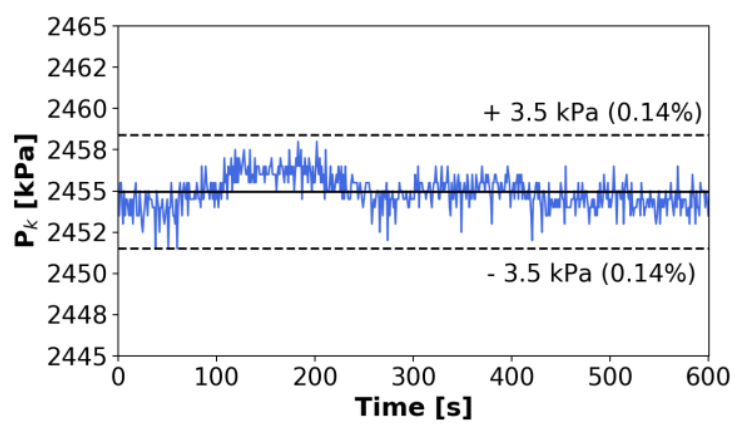

(b)

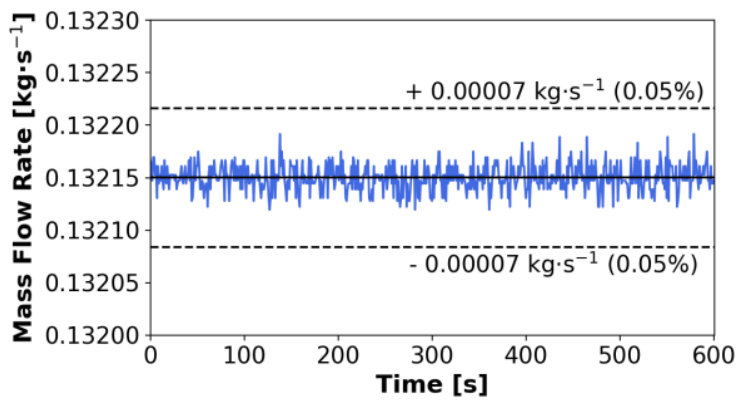


(c)

Fig. 3. Fluctuations of operating parameters of the highest heating production temperature steady-state test. (a) Evaporating pressure, (b) condensing pressure, (c) heat sink outlet temperature, (d) refrigerant mass flow rate.

T-s diagram of the of the highest heating production temperature steady-state test are shown in Fig. 4. In order to clarify the interpretation of T-s diagram, the cycle points are listed in accordance with the schematic diagram in Fig. 1.

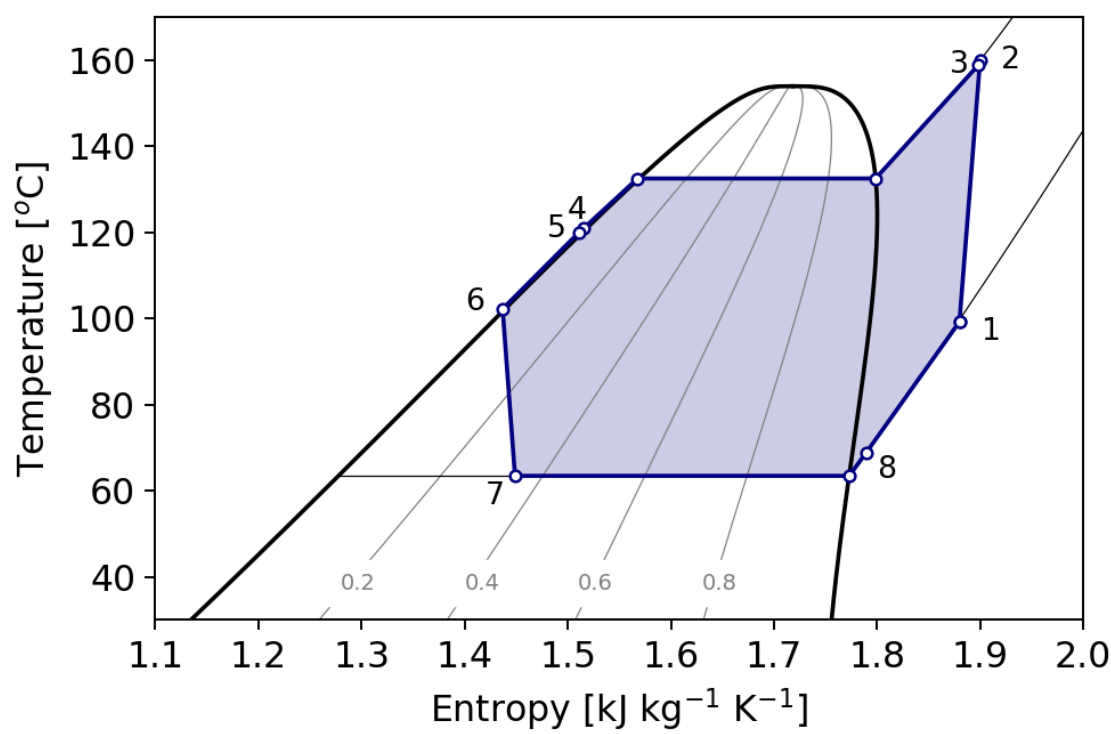

Fig. 4. T-s diagram of the highest heating production temperature steady-state test

\subsection{Data validation}

To evaluate the accuracy of the measurements, a comparison between the heat load supplied from the refrigerant and the heat supplied to the thermal oil at the condenser is carried out, including all the experimental tests as shown in Fig. 5.

The heating capacity at the refrigerant side is obtained as the product of the experimental refrigerant mass flow rate $\left(\dot{m}_{r e f}\right)$ and the heating effect, calculated as the measured refrigerant thermodynamic states at the condenser inlet $\left(h_{k, i n}\right)$ and outlet $\left(h_{k, \text { out }}\right)$. Hence the heating capacity is expressed as in Eq. (1).

$$
\dot{Q}_{k}=\dot{m}_{r e f}\left(h_{k, \text { in }}-h_{k, \text { out }}\right)
$$

Further, the heating capacity at the heat sink side is obtained using the measured thermal oil mass flow rate $\left(\dot{m}_{\text {sink }}\right)$ and the temperature difference between the condenser outlet $\left(T_{\text {sink,out }}\right)$ and inlet $\left(T_{\text {sink,in }}\right)$, as in Eq. (2).

$$
\dot{Q}_{\operatorname{sink}}=\dot{m}_{\sin k} c_{p, \operatorname{sink}}\left(T_{\sin k, \text { out }}-T_{\sin k, \text { in }}\right)
$$




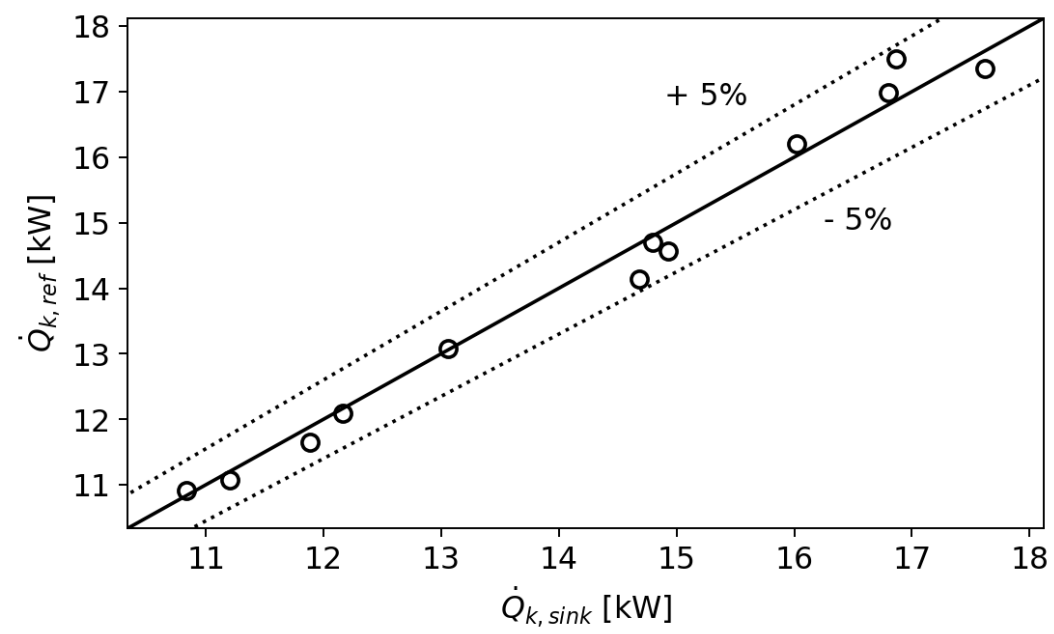

Fig. 5. Heating capacity at the condenser (comparing refrigerant and heat sink sides).

The condenser heat balance shows a good agreement between both sides, as all the experimental tests are within a deviation of $\pm 5 \%$. Moreover, the main steady-state at heat source temperature of $80{ }^{\circ} \mathrm{C}$ and heat sink temperature of $140{ }^{\circ} \mathrm{C}$ were validated through the repeatability of this condition, showing a deviation lower than $5 \%$ between the measured and calculated parameters of each measurement.

\subsection{Propagation of errors in the estimated parameters}

In this section we describe the uncertainty propagation methodology of the characteristic parameters. The uncertainty of the measurements consists of the systematic and random errors. While systematic errors produce an offset to the true value, the random errors scatter around the mean value. The influence of the systematic errors can be reduced or even corrected by calibrating the measuring system, owing to the reproducibility of the offset. Thus, the thermocouples and pressure transducers were calibrated in our laboratory in order to reduce the systematic error of the measurements. The measurement accuracies of the applied sensors are listed in Table 1.

On the other hand, random errors are not reproducible and therefore cannot be corrected. However, measurements often exhibit the characteristics of a normally distributed events and therefore, random errors can be characterised by statistical methods. In general, the series of measurements, extracted from the statistical population, can be described as follows:

$$
\bar{x} \pm \sigma_{x}
$$

where $\bar{x}$ is the arithmetic average, $\sigma_{x}$ is the empirical standard deviation, Eq. (4), $i$ indicates the measurement, and $n$ is the number of measurements.

$$
\sigma_{x}=\sqrt{\frac{1}{n-1}} \sum_{i=1}^{n}\left(x_{i}-\bar{x}\right)^{2}
$$

The confidence interval of the arithmetic average and the empirical standard deviation is $68.3 \%$. To obtain a $95.5 \%$ of confidence level, the empirical standard deviation is multiplied by 2 [27]. Finally, the uncertainty of the measurement $\bar{\sigma}_{x}$, which involves systematic and random errors, is obtained by the root-sum-of-squares (RSS) method.

However, there are interesting parameters that cannot be measured directly, but are derived from other parameters such as the temperature and pressure, which can be measured. Thus, the Gaussian law of error propagation can be applied to quantify the uncertainty of the derived parameters. When the quantity desired $Y$ is calculated as a function of one or more variables from a direct measurement, $Y=f\left(x_{1}, x_{2} x_{3}, \ldots, x_{k}\right)$, the standard deviation of the derived quantity is described by: 


$$
\sigma_{y}=\sqrt{\sum_{j=1}^{k}\left(\frac{\partial Y}{\partial x_{j}}\right)^{2} \bar{\sigma}_{x}^{2}}
$$

where the index $j$ describes the influencing variables of the derived quantity $Y$. The software EES [28] has been used to implement the partial derivative of a function to calculate the uncertainty of the desired quantity with the uncertainty of the measured quantities. Moreover, REFPROP 10.0 could be implemented in EES to provide the refrigerant properties. In summary, the uncertainty propagation was calculated with the methodology explained above, introducing the uncertainty of the measurement $\bar{\sigma}_{x}$ calculated with the systematic and random error, in the EES software and using REFPROP 10.0 as refrigerant database.

\subsection{Exergy analysis}

As well as the energetic (first law) analysis of the HTHP prototype, an exergetic (second law) analysis can help to identify the maximum potential work of a given measure point with respect to the reference state. This analysis provides useful information to determine the efficient use of the available energy and therefore, understand the direction of potential improvements. Vapour compression cycles have several irreversibility sources (exergy destruction) that separate the real performance from the ideal one. Accordingly, the main objective of this section is to evaluate the exergy destruction (irreversibility) and efficiency of each cycle component.

The total and the specific exergy of a fluid is:

$$
\begin{gathered}
\dot{E} x=\dot{m} \cdot e x \\
e x=\left(h-h_{o}\right)-T_{o}\left(s-s_{o}\right)
\end{gathered}
$$

where $h$ is the specific enthalpy, $s$ is the specific entropy and $h_{o}, s_{o}$ and $T_{o}$ correspond to the entropy, enthalpy and temperature at the dead state. Because of the variation of the heat source pressure and temperature in each measurement point, the temperature of the dead state $T_{o}$ has been selected as $T_{\text {source,out }}-\Delta T$, being $\Delta T 20 \mathrm{~K}$, but other reference can be selected. The difference between $T_{\text {source, out }}$ and evaporation temperature are between $2-10^{\circ} \mathrm{C}$, which increases as the temperature lift decreases. Finally, the refrigerant reference pressure $\left(P_{o}\right)$ is taken as the saturation pressure at $T_{o}[29]$.

The exergy destruction, $\dot{E} x_{d, t o t}$, represents the real energy losses that cannot be identified in an energy balance, it can be expressed as shown in Eq. (8) as general expression for any control volume.

$$
\dot{E} x_{d, t o t}=\sum\left(1-\frac{T_{0}}{\bar{T}}\right) \dot{Q}-\dot{W}_{\text {in }}+\sum_{\text {in }} \dot{m} \cdot e x-\sum_{\text {out }} \dot{m} \cdot e x
$$

The entropy-averaged temperatures $\bar{T}$ correspond to the average temperature in the T-s diagram of the secondary fluids, thermal oil in the condenser, and, in this case, thermal oil in the evaporator. For constant pressure and heating capacity, the entropy-averaged temperatures can be calculated using Eq. (9) [30].

$$
\bar{T}=\frac{h_{\text {out }}-h_{\text {in }}}{S_{\text {out }}-s_{\text {in }}}=\frac{T_{\text {out }}-T_{\text {in }}}{\ln \left(\frac{T_{\text {out }}}{T_{\text {in }}}\right)}
$$


In this study, the overall exergy destruction for the vapour compression system is obtained as the accumulation of the exergy destruction in each cycle component, as in Eq. (10).

$$
\dot{E} x_{d}=\dot{E} x_{d, c}+\dot{E} x_{d, c o n d}+\dot{E} x_{d, e v}+\dot{E} x_{d, e x}+\dot{E} x_{d, I H X}
$$

Based on the previous expressions, the exergy destruction for each component is defined according to the following equations:

$$
\begin{aligned}
& \dot{E} x_{d, c}=\dot{W}_{c}+\dot{m}_{r e f} \cdot\left(e x_{\text {out }}-e x_{\text {in }}\right)=\dot{W}_{c}+\dot{m}_{r e f} \cdot\left[\left(h_{\text {out }}-h_{\text {in }}\right)-T_{0} \cdot\left(s_{\text {out }}-\right.\right. \\
& \left.\left.s_{\text {in }}\right)\right] \\
& \dot{E} x_{d, \text { cond }}=\dot{m}_{r e f} \cdot\left[\left(h_{k, \text { in }}-h_{k, \text { out }}\right)-T_{0} \cdot\left(s_{k, \text { in }}-s_{k, \text { out }}\right)\right]-\dot{Q}_{k} \cdot\left(1-\frac{T_{0}}{\bar{T}_{k}}\right) \\
& \dot{E} x_{d, \text { evap }}=\dot{Q}_{o} \cdot\left(1-\frac{T_{0}}{\bar{T}_{o}}\right)-\dot{m}_{r e f} \cdot\left[\left(h_{o, \text { in }}-h_{o, \text { out }}\right)-T_{0} \cdot\left(s_{o, \text { in }}-s_{o, \text { out }}\right)\right] \\
& \left.\dot{E} x_{d, e v}=\dot{m}_{\text {ref }} \cdot T_{0} \cdot\left(s_{\text {ex,out }}-s_{\text {ex,in }}\right)\right] \\
& \dot{E} x_{d, I H X}=\dot{m}_{\text {ref }}\left(\left[\left(h_{I H X, l i q, \text { in }}-h_{I H X, l i q, o u t}\right)-\left(h_{I H X, v a p, o u t}-h_{I H X, v a p, \text { in }}\right)\right]\right. \\
& \left.-T_{0}\left[\left(s_{I H X, l i q, \text { in }}-s_{I H X, l i q, \text { out }}\right)-\left(s_{I H X, \text { vap }, \text { out }}-s_{I H X, \text { vap }, \text { in }}\right)\right]\right)
\end{aligned}
$$

The exergy efficiency can be defined in the vapour compression cycles as the ratio of the minimum power required by a reversible system to the actual exergy input. The exergy analysis is carried out using the following equations:

$$
\begin{aligned}
& \psi_{c}=\frac{\dot{m}_{r e f} \cdot\left[\left(h_{\text {out }}-h_{\text {in }}\right)-T_{0} \cdot\left(s_{\text {out }}-s_{\text {in }}\right)\right]}{\dot{W}_{c}} \\
& \psi_{\text {cond }}=\frac{\dot{m}_{r e f} \cdot\left[\left(h_{k, \text { out }}-h_{k, \text { in }}\right)-T_{0} \cdot\left(s_{k, \text { out }}-s_{k, \text { in }}\right)\right]}{\dot{Q}_{k} \cdot\left(1-\frac{T_{0}}{\bar{T}_{k}}\right)} \\
& \psi_{\text {evap }}=\frac{\dot{m}_{r e f} \cdot\left[\left(h_{o, \text { in }}-h_{o, \text { out }}\right)-T_{0} \cdot\left(s_{o, \text { in }}-s_{o, \text { out }}\right)\right]}{\dot{Q}_{o} \cdot\left(1-\frac{T_{0}}{\bar{T}_{o}}\right)} \\
& \psi_{e v}=\frac{\left(h_{e v, o u t}-h_{0}\right)-T_{0} \cdot\left(s_{e v, \text { out }}-s_{o}\right)}{\left(h_{e v, \text { in }}-h_{0}\right)-T_{0} \cdot\left(s_{e v, \text { in }}-s_{o}\right)} \\
& \psi_{I H X}=\frac{\left(h_{I H X, v a p, \text { out }}-h_{I H X, v a p, \text { in }}\right)-T_{0} \cdot\left(s_{I H X, v a p, \text { out }}-s_{I H X, \text { vap }, \text { in }}\right)}{\left(h_{I H X, \text { liq }, \text { in }}-h_{I H X, l i q, \text { out }}\right)-T_{0} \cdot\left(s_{I H X, \text { liq }, \text { in }}-s_{I H X, l i q, \text { out }}\right)}
\end{aligned}
$$

The total exergy efficiency of the high-temperature heat pump is obtained using Eq. (21).

$$
\psi_{H T H P}=\frac{\dot{W}_{c}-\dot{E} x_{d, t o t}}{\dot{W}_{c}+\dot{Q}_{o} \cdot\left(1-\frac{T_{0}}{\bar{T}_{o}}\right)}
$$


Finally, the relative irreversibility (IR) provides the useful information of the irreversibility contribution of each component over the whole system, and is calculated using Eq. (22). This parameter shows the highest potential improvement for each component from an exergetic point of view. The higher is the RI, the greater are the potential improvements.

$$
R I_{i}=\frac{\dot{E} x_{d, i}}{\dot{E} x_{d, t o t}}
$$

\subsection{Prototype design, development and analysis process}

The experimental results of HTHP prototype presented in this paper required several essential previous steps as illustrated in Fig. 6. This design, development, and analysis methodology establishes the baseline for future prototypes development and alternative low-GWP refrigerants evaluation.

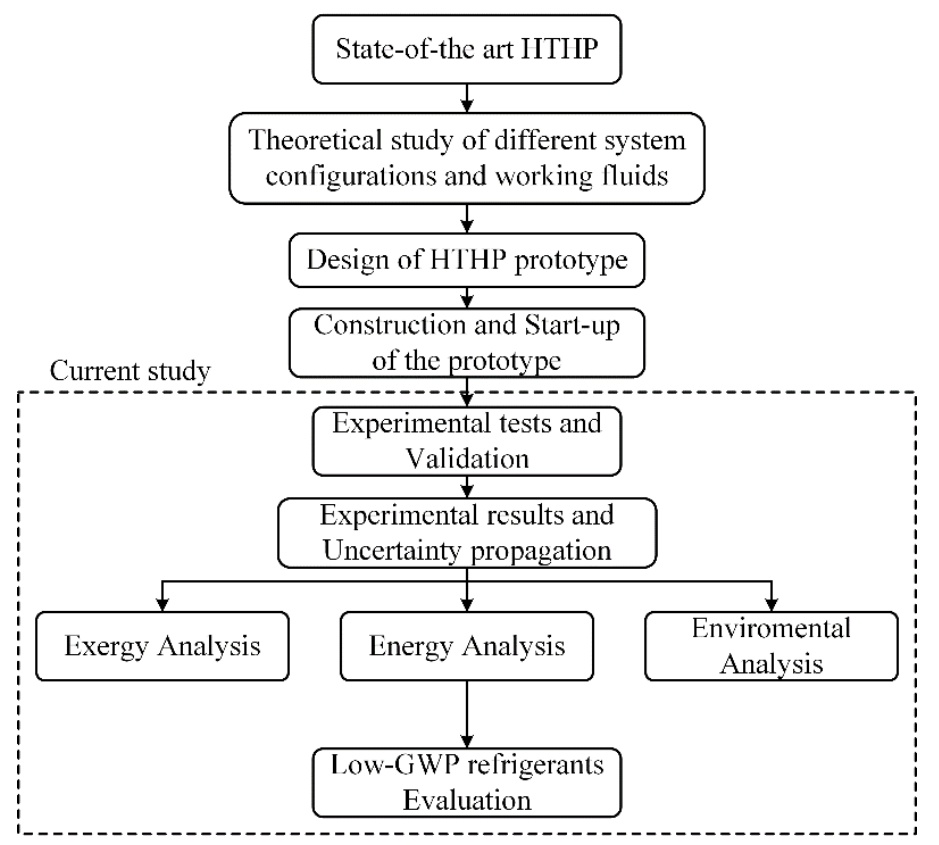

Fig. 6. Diagram methodology flow of the novel HTHP prototype design, development, and analysis.

\section{Results and discussions}

In this section, the results of the experimental investigation are given and discussed. Firstly, the energy performance results are presented and complemented with the exergy analysis of the experimental prototype. Secondly, alternative low-GWP alternative refrigerants are evaluated as potential candidates in HTHPs. Finally, HTHP integration as a waste heat recovery system in CHP installation are proposed along with the environmental emissions analysis.

\subsection{Energy performance results}

In this subsection, the compressor performance, heating capacity, and COP results are presented and discussed for heat sink temperatures between 90 and $140{ }^{\circ} \mathrm{C}$ and heat source temperatures between 60 and $80{ }^{\circ} \mathrm{C}$. The results are presented for different heat sink temperatures and temperature lifts, which, in this study, is considered as the temperature difference between the condenser outlet $\left(T_{\text {sink,out }}\right)$ and the evaporator inlet $\left(T_{\text {source,in }}\right)$. 


\subsubsection{Compressor performance}

The directly measured compressor power consumption is presented in Fig. 7. This parameter is highly influenced by the heat sink temperature due to the increment results in higher mass flow rate, corresponding to the specific compression work. The values are not significantly affected by the temperature lift but by two other effects. Whereas the mass flow rate decreases at low evaporation temperatures, the specific work increases as illustrates Eq. (23). As a result, the compressor power consumption value remains at a similar level.

$$
\dot{W}_{C}=\dot{m}_{r e f} \Delta h_{c}
$$

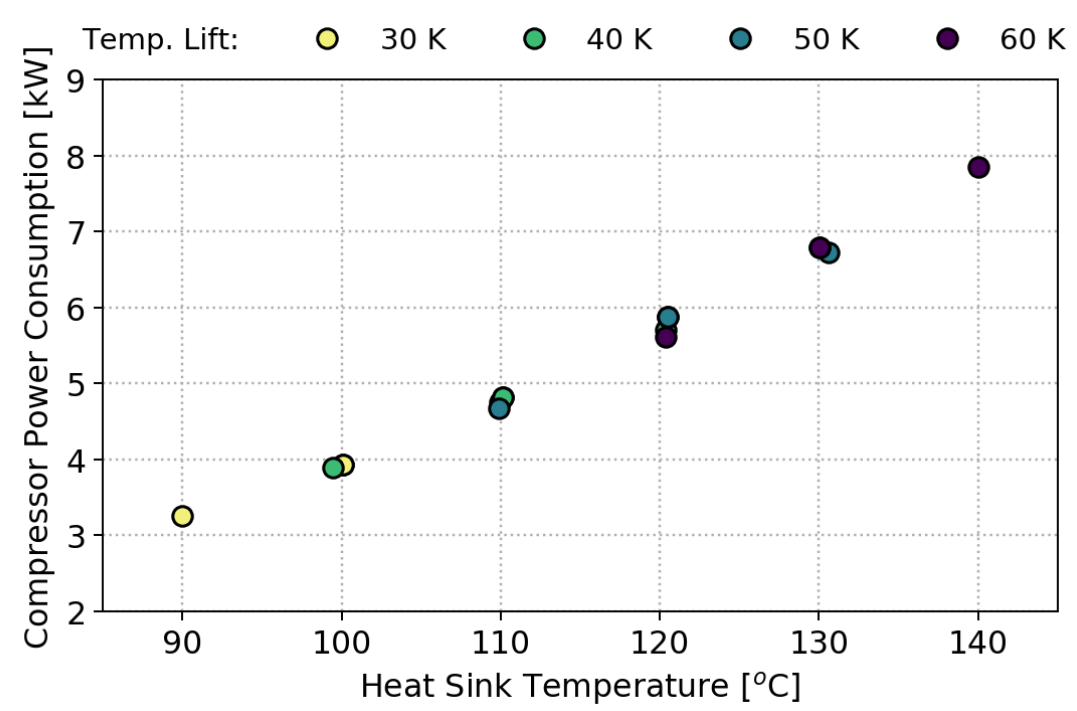

Fig. 7. Experimental compressor power consumption variation as a function of the heat sink temperature.

Fig. 8 show the results of the mass flow rate measued directly. At constant compressor rotational speed, the mass flow rate is proportional to the suction density of the refrigerant, which is calculated using the suction pressure and temperature measurements. A lower heat source temperature has a detrimental effect on the mass flow rate because it reduces the volumetric efficiency and suction density. The mass flow rate is highly influenced by the suction temperature, which is directly related to the heat source temperature. Thus, higher heat source or heat sink temperatures produce an increase of the mass flow rate, which can considerably influence the performance parameters. Hence, an increment of the heat source temperature produces a decrease of the suction density and therefore, an increase of the mass flow rate. Moreover, higher heat sink temperatures with constant heat source temperatures produce an increment in the internal heat exchanger (IHX) effectiveness, which induces a reduction in the suction density and accordingly, an increment in the mass flow rate. 


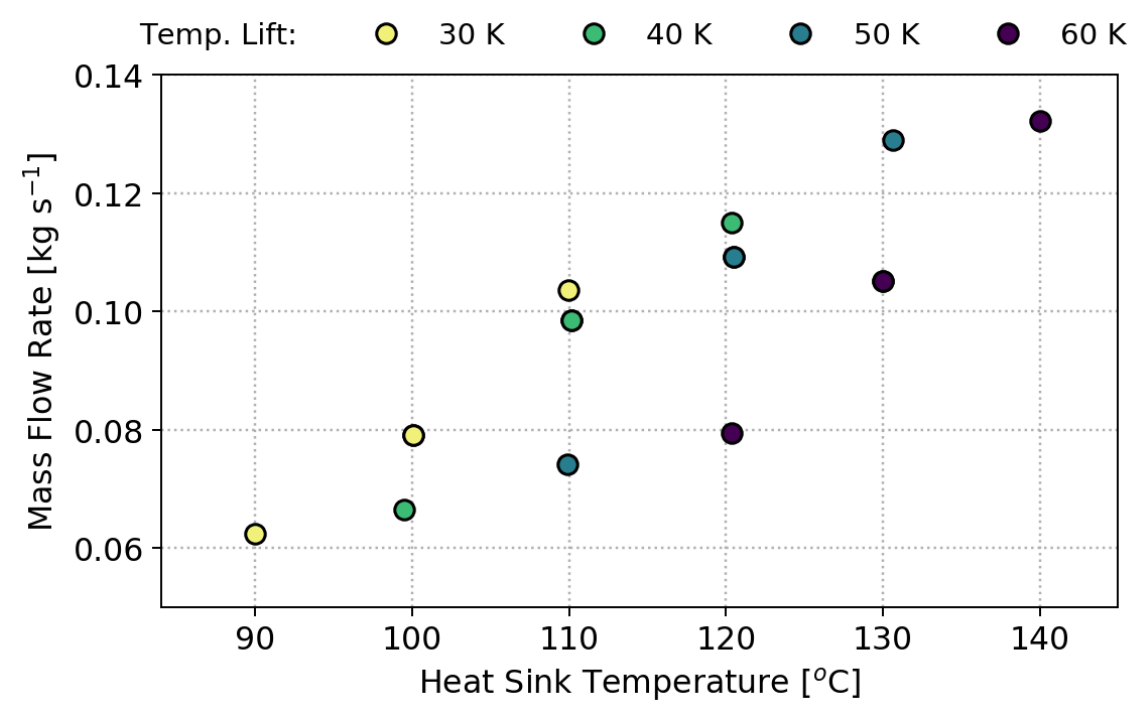

Fig. 8. Experimental mass flow rate variation regarding the heat sink temperature.

Finally, the discharge temperature of the compressor affects the heat transferred to the refrigerant during the evaporation, superheating (in the evaporator, internal heat exchanger, suction line, and compressor suction), and compression processes. This is considered the most critical temperature point of the refrigerant in the vapour compression system, especially for high-temperature applications. The discharge temperature affects the maximum temperature achievable by the heat sink fluid and therefore, determines the maximum temperature range of the application. As expected, the discharge temperature is highly affected by the heat sink temperature. As the heat sink temperature increases, the discharge temperature increases almost proportionally, as shown Fig. 9. The highest discharge temperature achieved with a heat sink temperature of $140{ }^{\circ} \mathrm{C}$ is 160 ${ }^{\circ} \mathrm{C}$. Although this discharge temperature value remains under that for the thermal stability of the refrigerant and installation materials, further developments with high production temperatures will require special attention to this parameter due to the materials and fluid stability issues at such high-temperatures.

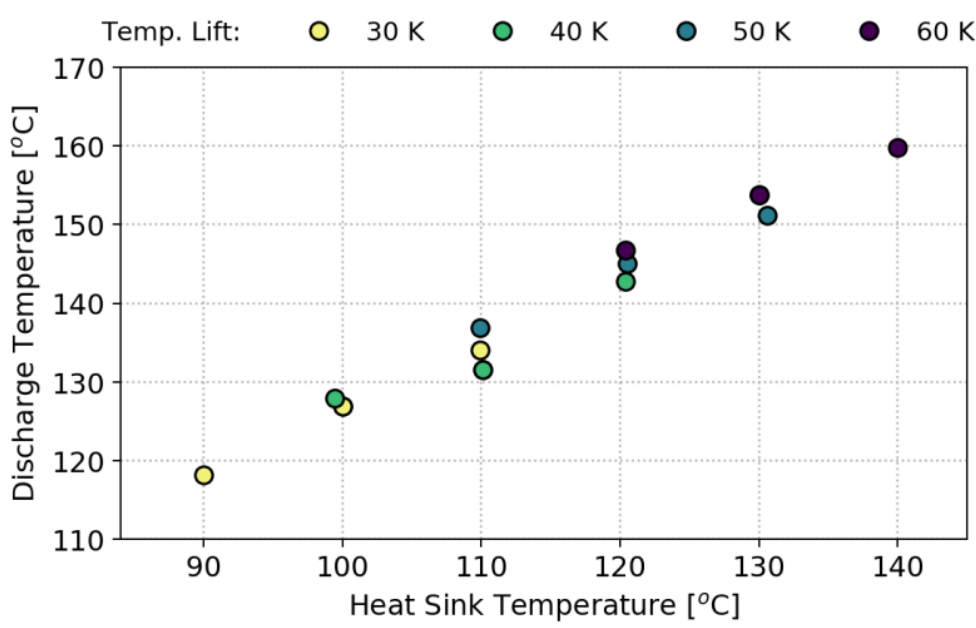

Fig. 9. Experimental discharge temperature as function of the heat sink temperature.

\subsubsection{Heating capacity}

The heating capacity at the condenser (refrigerant side), which has been validated in a heat balance in Section 3.3, is shown in Fig. 10, and the estimated uncertainty propagation is described in Table 3. 
Table 3. Summary of the heating capacity values along with the absolute and relative uncertainties.

\begin{tabular}{|c|c|c|c|c|c|}
\hline $\begin{array}{c}T_{\text {sink,out }} \\
\left({ }^{\circ} \mathrm{C}\right)\end{array}$ & $\begin{array}{c}T_{\text {source,in }} \\
\left({ }^{\circ} \mathrm{C}\right)\end{array}$ & $\begin{array}{c}\text { Temperature } \\
\text { Lift }(\mathrm{K})\end{array}$ & $\begin{array}{c}\text { Heating } \\
\text { Capacity } \\
(\mathrm{kW})\end{array}$ & $\begin{array}{c}\text { Absolute } \\
\text { Uncertainty }\end{array}$ & $\begin{array}{c}\text { Relative } \\
\text { Uncertainty }\end{array}$ \\
\hline 90.0 & 60.0 & 30 & 10.92 & \pm 0.62 & $\pm 5.65 \%$ \\
\hline 100.1 & 70.0 & 30 & 13.07 & \pm 0.50 & $\pm 3.84 \%$ \\
\hline 109.9 & 80.0 & 30 & 16.20 & \pm 0.58 & $\pm 3.56 \%$ \\
\hline 99.5 & 59.8 & 40 & 11.07 & \pm 0.43 & $\pm 3.91 \%$ \\
\hline 110.1 & 70.9 & 40 & 14.57 & \pm 0.52 & $\pm 3.55 \%$ \\
\hline 120.4 & 80.7 & 40 & 16.99 & \pm 0.54 & $\pm 3.15 \%$ \\
\hline 109.9 & 59.8 & 50 & 11.64 & \pm 0.67 & $\pm 5.73 \%$ \\
\hline 120.5 & 69.4 & 50 & 14.14 & \pm 0.52 & $\pm 3.67 \%$ \\
\hline 130.6 & 80.4 & 50 & 17.35 & \pm 0.57 & $\pm 3.29 \%$ \\
\hline 120.4 & 59.4 & 60 & 12.09 & \pm 0.47 & $\pm 3.87 \%$ \\
\hline 130.0 & 70.4 & 60 & 14.69 & \pm 0.54 & $\pm 3.64 \%$ \\
\hline 140.0 & 80.2 & 60 & 17.51 & \pm 0.56 & $\pm 3.21 \%$ \\
\hline
\end{tabular}

The heat absorbed in the evaporator was revalorised, becoming a useful heat upon transfer to the secondary fluid. The relevance of the heat source and sink operating temperatures is reflected in this parameter, which is affected by the refrigerant mass flow rate and the enthalpy difference at the condenser. This HTHP prototype can produce between 16.20 and $17.51 \mathrm{~kW}$ of heat at the highest heat source temperature, and between 10.92 and $12.09 \mathrm{~kW}$ at the lowest temperature (60 $\left.{ }^{\circ} \mathrm{C}\right)$. The heat sink temperature has a small effect on this parameter, and a variation of the source does not deteriorate the heat production. Thus, attention must be paid to the heat source temperature during the HTHP design stage.

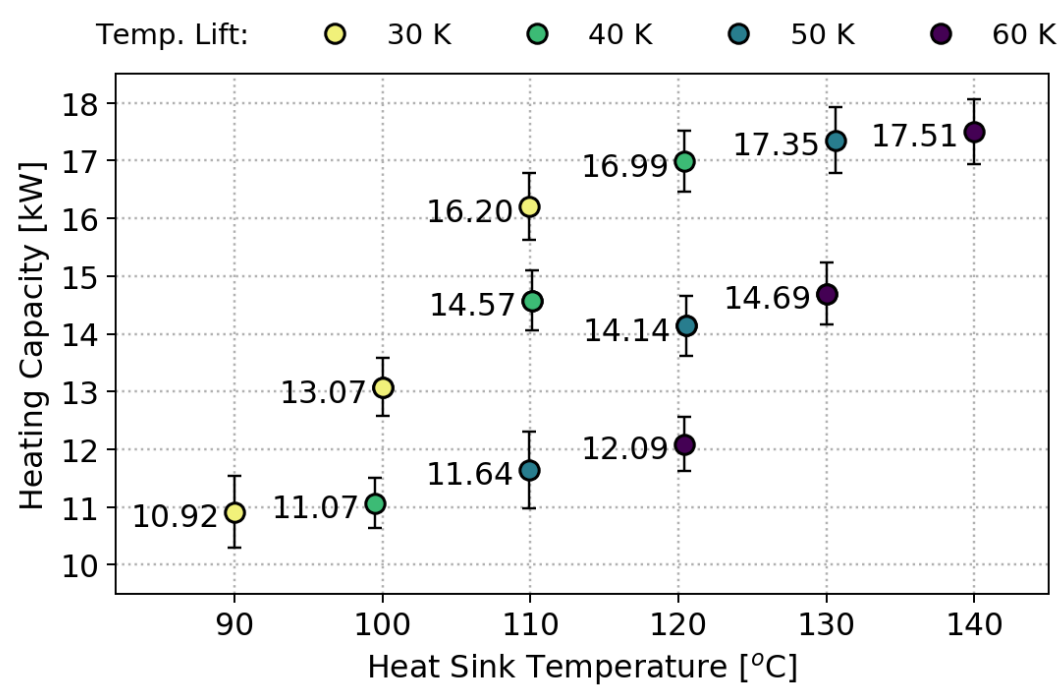

Fig. 10. Experimental heating capacity at the tested conditions with the estimated uncertainty propagation.

\subsubsection{Coefficient of Performance (COP)}

The COP of the HTHP is obtained using Eq. (24) and the previously presented values of the compressor power consumption and heating capacity.

$$
C O P=\frac{\dot{Q}_{k}}{\dot{W}_{C}}
$$


Fig. 11 shows an overview of the experimental COP results over the different operating points analysed.

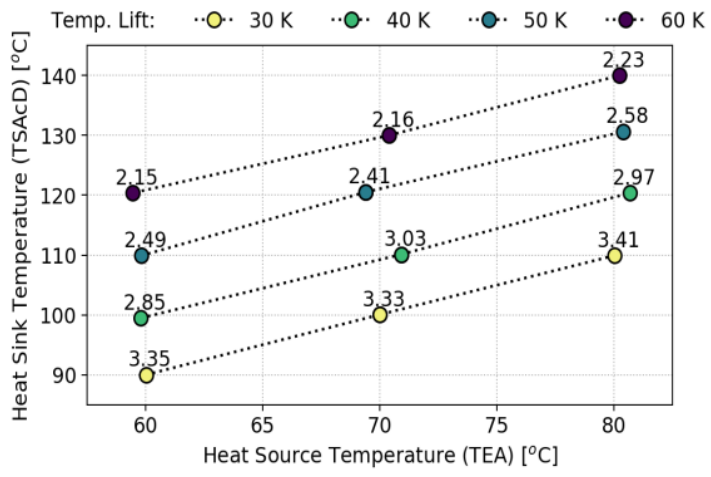

(a)

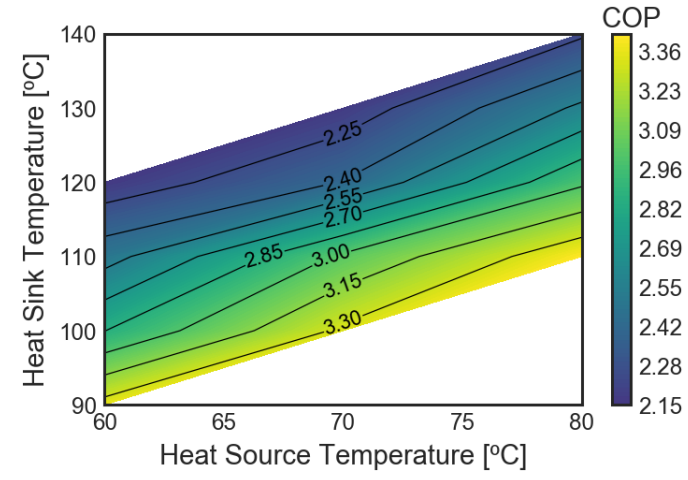

(b)

Fig. 11 Experimental COP results at different operating points: (a) Experimental steady-state of the preliminary COP results and (b) COP mapping of the experimental results.

Although the compressor power consumption and heating capacity increase as the heat sink temperature increases, the specific enthalpy difference at the compressor presents an increase of the specific enthalpy differences at the condenser. Thus, the refrigerant mass flow rate has no direct effect on the COP; rather, the major effect is caused by the compression ratio and therefore the temperature lift, as shown in Fig. 12. Consequently, four levels of COP can be observed, corresponding to the four temperature lifts considered, along with the uncertainties and errors presented in Table 4.

Table 4. Summary of the COP values along with the absolute and relative uncertainties.

\begin{tabular}{|c|c|c|c|c|c|}
\hline $\begin{array}{c}T_{\text {sink,out }} \\
\left({ }^{\circ} \mathrm{C}\right)\end{array}$ & $\begin{array}{c}T_{\text {source, in }} \\
\left({ }^{\circ} \mathrm{C}\right)\end{array}$ & $\begin{array}{c}\text { Temperature } \\
\text { Lift }(\mathrm{K})\end{array}$ & COP & $\begin{array}{c}\text { Absolute } \\
\text { Uncertainty }\end{array}$ & $\begin{array}{c}\text { Relative } \\
\text { Uncertainty }\end{array}$ \\
\hline 90.0 & 60.0 & 30 & 3.35 & \pm 0.21 & $\pm 6.15 \%$ \\
\hline 100.1 & 70.0 & 30 & 3.33 & \pm 0.15 & $\pm 4.38 \%$ \\
\hline 109.9 & 80.0 & 30 & 3.41 & \pm 0.14 & $\pm 4.07 \%$ \\
\hline 99.5 & 59.8 & 40 & 2.85 & \pm 0.13 & $\pm 4.44 \%$ \\
\hline 110.1 & 70.9 & 40 & 3.03 & \pm 0.12 & $\pm 4.06 \%$ \\
\hline 120.4 & 80.7 & 40 & 2.97 & \pm 0.11 & $\pm 3.66 \%$ \\
\hline 109.9 & 59.8 & 50 & 2.49 & \pm 0.15 & $\pm 6.06 \%$ \\
\hline 120.5 & 69.4 & 50 & 2.41 & \pm 0.10 & $\pm 4.13 \%$ \\
\hline 130.6 & 80.4 & 50 & 2.58 & \pm 0.10 & $\pm 3.76 \%$ \\
\hline 120.4 & 59.4 & 60 & 2.15 & \pm 0.09 & $\pm 4.27 \%$ \\
\hline 130.0 & 70.4 & 60 & 2.16 & \pm 0.09 & $\pm 4.07 \%$ \\
\hline 140.0 & 80.2 & 60 & 2.23 & \pm 0.08 & $\pm 3.66 \%$ \\
\hline
\end{tabular}

It is observed that the available waste heat and the heat demand conditions have a great influence on the energy efficiency of the HTHP system. Hence, the highest COP, with a value of 3.41, is achieved at a $110{ }^{\circ} \mathrm{C}$ heat sink temperature and $80^{\circ} \mathrm{C}$ heat source temperature. Nevertheless, the most interesting performance value for this application is achieved at heat source temperature of $80{ }^{\circ} \mathrm{C}$ and heat sink temperature of $140{ }^{\circ} \mathrm{C}$ with a COP value of 2.23 . This performance value is considered relevant based on the comparison of other similar experimental installations with single stage configuration with IHX, using HFC-245fa as working fluid [8]. Nevertheless, further investigations on different configurations and working fluids could improve the energy efficiency of this technology, and make it a sustainable energy system. 


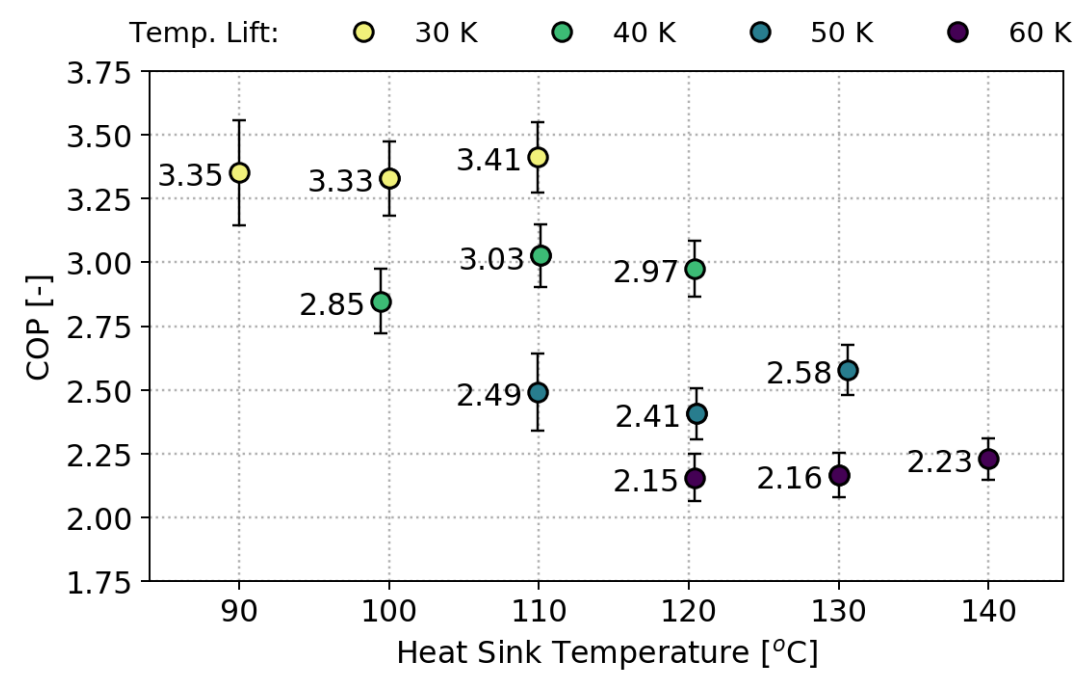

Fig. 12. Experimental COP at the tested conditions with the estimated uncertainty propagation.

\subsubsection{Influence of the IHX}

Internal heat exchanger (IHX) becomes an interesting component that presents high influence in the system performance, especially in high-temperature applications. Hence, estimated IHX influence in low-GWP alternatives based on experimental data can provide useful information for future designs or drop-in replacements. Firstly, experimental IHX effectiveness results, shown in Fig. 13, is increasing as the heat sink temperature increases and therefore, this parameter will be critical for higher heating production temperature. Thus, the IHX influence is studied for the 140 ${ }^{\circ} \mathrm{C}$ heat sink temperature and $80{ }^{\circ} \mathrm{C}$ heat source temperature condition (highest temperature lift tested). The resulting experimental value of the IHX effectiveness $\left(\varepsilon_{I H X}\right)$ in HFC-245fa is 0.38 . This value is assumed constant for each refrigerant for the performance parameters calculations in a basic vapour compression cycle with IHX.

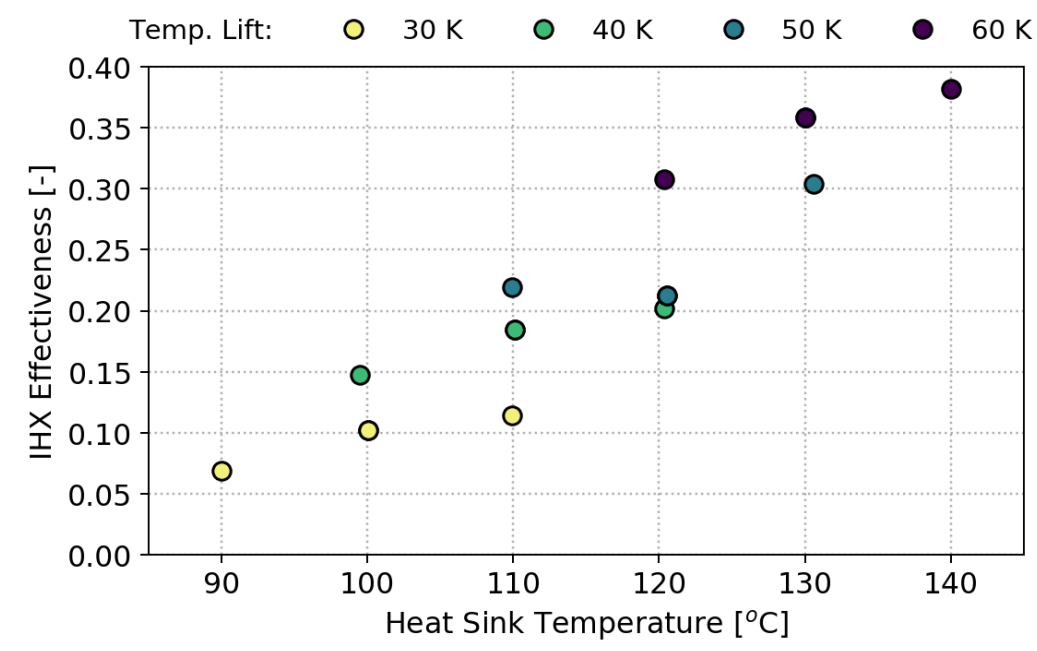

Fig. 13. Experimental IHX effectiveness in the different operating conditions.

\subsection{Exergy results}

A general overview of the exergy efficiency, destruction, and RI of the main components and the overall vapor compression circuit is provided in Table 5 and 6 . The maximum, minimum and average values of the experimental sets are included. 
Table 5. Summary of the experimental exergy efficiency results.

\begin{tabular}{|c|c|c|c|c|c|c|c|}
\hline $\begin{array}{c}\text { Exergy } \\
\text { Parameters }\end{array}$ & Measure & Compressor & Condenser & Evaporator & $\begin{array}{c}\text { Expansion } \\
\text { Valve }\end{array}$ & IHX & System \\
\hline $\begin{array}{c}\text { Exergy } \\
\text { Efficiency }\end{array}$ & Max & 63.27 & 96.24 & 49.54 & 27.54 & 73.92 & 30.80 \\
\cline { 2 - 8 }$[\%]$ & Ave & 60.30 & 90.01 & 41.74 & 27.44 & 51.08 & 25.48 \\
\cline { 2 - 8 } & Min & 58.21 & 87.91 & 32.63 & 27.28 & 27.29 & 20.94 \\
\hline
\end{tabular}

Table 6. Summary of the experimental exergy destruction and RI results.

\begin{tabular}{|c|c|c|c|c|c|c|c|}
\hline $\begin{array}{c}\text { Exergy } \\
\text { Parameters }\end{array}$ & Measure & Compressor & Condenser & Evaporator & $\begin{array}{c}\text { Expansion } \\
\text { Valve }\end{array}$ & IHX & Total \\
\hline $\begin{array}{c}\text { Exergy } \\
\text { Destruction } \\
{[\mathrm{kW}]}\end{array}$ & Max & 2.71 & 0.63 & 0.41 & 1.21 & 0.44 & 4.83 \\
\cline { 2 - 9 } & Ave & 1.78 & 0.48 & 0.22 & 0.80 & 0.21 & 3.51 \\
\hline \multirow{3}{*}{ RI [\%] } & Min & 1.12 & 0.36 & 0.09 & 0.45 & 0.05 & 2.29 \\
\cline { 2 - 9 } & Ave & 56.70 & 17.27 & 12.68 & 26.58 & 11.26 & - \\
\cline { 2 - 9 } & Min & 45.62 & 14.26 & 6.91 & 22.54 & 5.65 & - \\
\hline
\end{tabular}

From this information, one can see that in the expansion valve the exergy efficiency is very small compared to that in the other components. Given the logarithmic mean temperature difference between the secondary fluids and the refrigerant, the exergy efficiency is higher in the condenser than in the evaporator.

The RI of each component is represented graphically in Fig. 14. The compressor and the expansion valve are the components that show the highest RI values, with averages of 50.62 and $22.54 \%$, respectively. Hence, the compressor becomes the most influent component in the vapour compression system and the main source of system performance improvements. This is the case because the compressor is the cycle component with the highest mechanical and isentropic losses and therefore, the component with the higher reversibility of the system. Improvements in the compressor and the expansion valve will increase the energy efficiency of the whole installation.

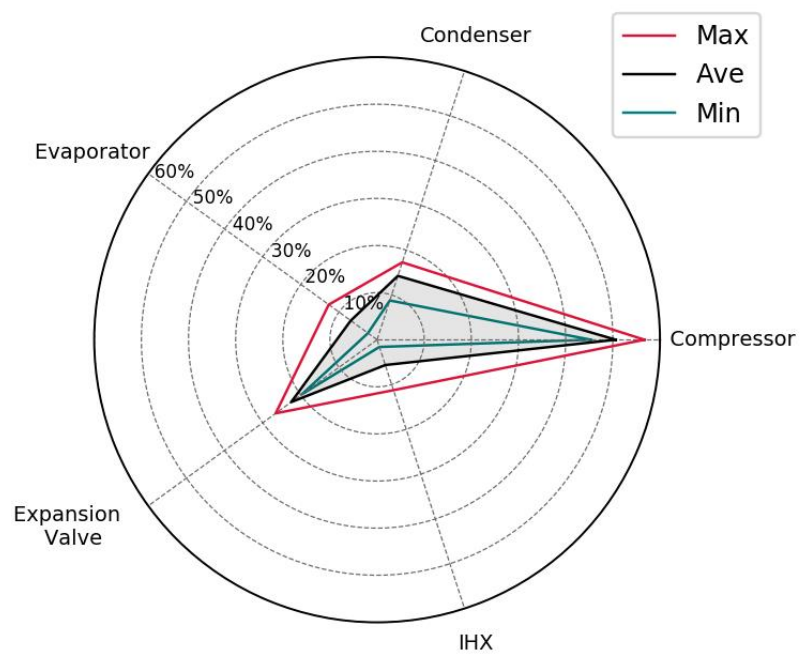

Fig. 14. RI diagram of each vapour compression component

Fig. 15 shows the exergy diagram obtained at heat sink temperature of $140{ }^{\circ} \mathrm{C}$ and heat source temperature of $80^{\circ} \mathrm{C}$. This figure helps to understand that a big part of the exergy is lost in the compressor, followed by the expansion valve. Thus, the experimental exergy analysis of this HTHP prototype installation provides useful information on the main source of potential performance improvements. In this case, the major exergy destruction occurs at the compressor, which could be improved in future designs, by developing novel lubricant oils and mechanical construction designs. Furthermore, the expansion valve is the cycle component with the second 
highest value of exergy destruction. Accordingly, the number of studies on ejectors as alternatives to expansion valves have increased recently and the performance of HTHPs are improving.

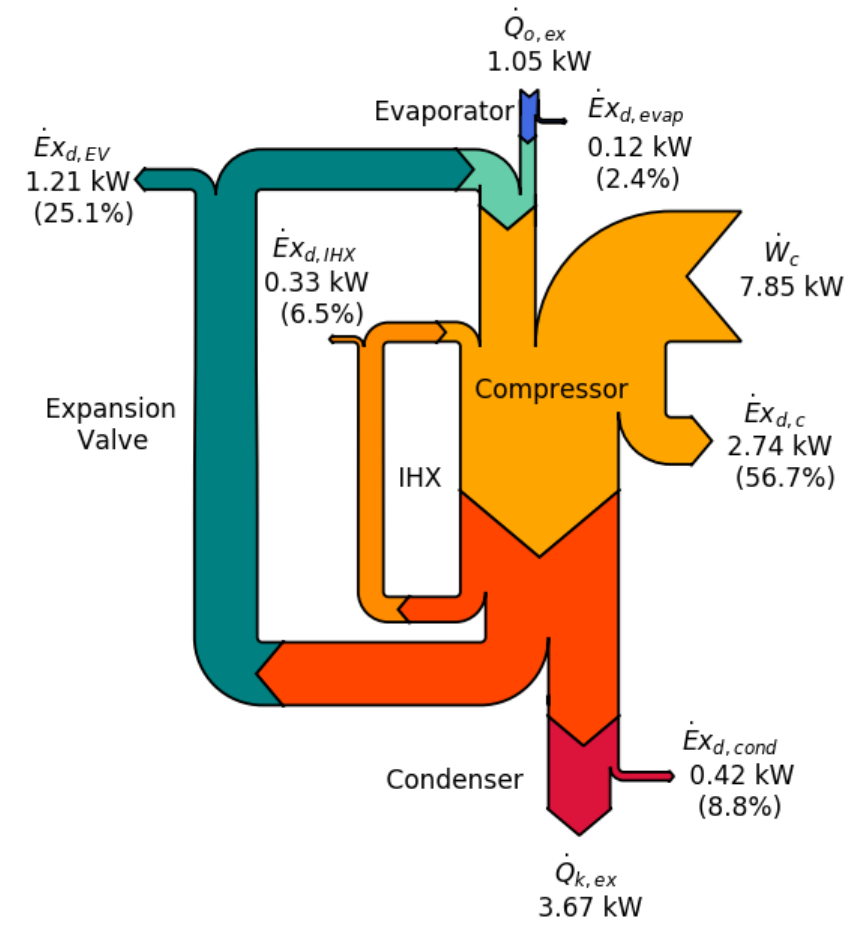

Fig. 15. Sankey diagram of the exergy flows in the HTHP system operating at heat sink temperature of $140^{\circ} \mathrm{C}$ and heat source temperature of $80^{\circ} \mathrm{C}$.

\subsection{Semi-empirical low-GWP refrigerants assessment}

To provide more in-depth knowledge of the potential of alternative low-GWP refrigerants, theoretical evaluations of HCFO-1224yd(Z), HCFO-1233zd(E), and HFO-1336mzz(Z), selected because of their similarities with the traditional HFC-245fa, were carried out, as shown in Fig. 16. The alternative refrigerant present similar or even higher critical temperatures than HFC245fa. Although HCFO-1224yd(Z) and HCFO-1233zd(E) show similar saturated vapour curve slopes, different from that of HFO-1336mzz(Z).

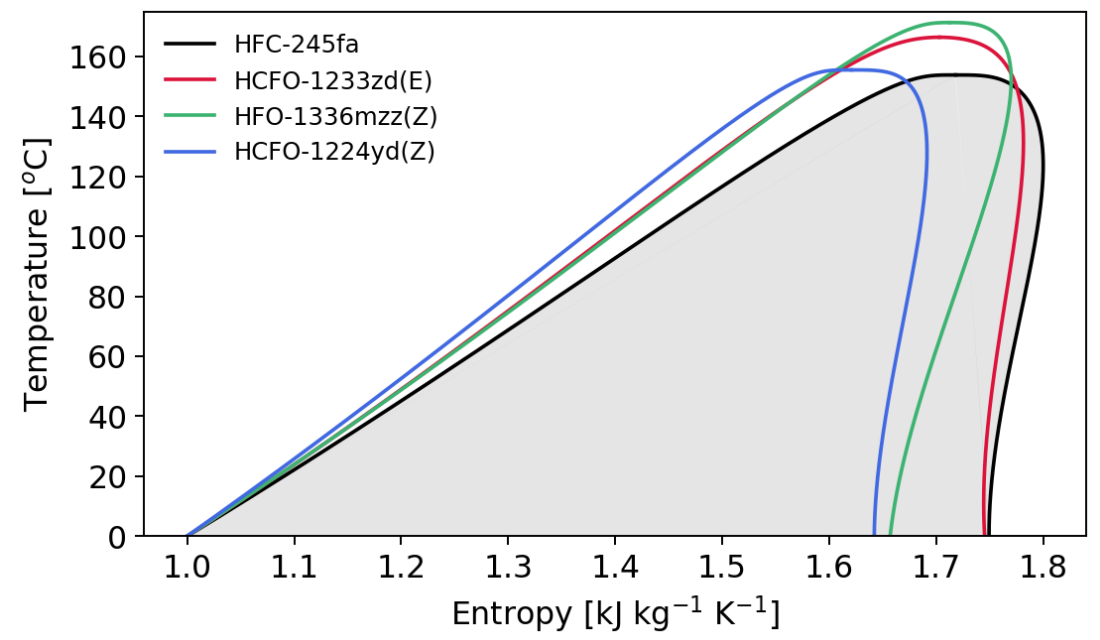

Fig. 16. T-s diagram of the low-GWP refrigerants alternative to HFC-245fa: HCFO-1233zd(E), HCFO-1224yd(Z) and HFO-1336mzz(Z). 
Table 7 shows the main thermodynamic properties of HFC-245fa and the potential alternatives refrigerants. It can be seen from the table that the suction density of HCFO-1233zd(E) and $\mathrm{HCFO}-1224 \mathrm{yd}(\mathrm{Z})$ are close to the reference fluid, while that of HFO-1336mzz(Z) is lower. Thus, a higher suction volumetric flow rate is expected for HFO- $1336 \mathrm{mzz}(\mathrm{Z})$ than the other refrigerants, which causes a decrease of the volumetric heating capacity. Hence, the thermodynamic properties and saturated vapour slope differences of HFO-1336mzz(Z) compared to the other refrigerants will be the main cause of the distinctive behaviour that this refrigerant shows in the results.

Table 7. Properties of HFC-245fa and the alternative low GWP refrigerants.

\begin{tabular}{|c|c|c|c|c|}
\hline Parameters & $\begin{array}{c}\text { HFC- } \\
245 f a\end{array}$ & HFO-1336mzz(Z) & HCFO-1233zd(E) & HCFO-1224yd(Z) \\
\hline $\begin{array}{c}\text { Molecular weight } \\
\left(\mathrm{g} \cdot \mathrm{mol}^{-1}\right)\end{array}$ & 134.05 & 164.06 & 130.50 & 148.49 \\
\hline $\begin{array}{c}\text { Critical } \\
\text { temperature }\left({ }^{\circ} \mathrm{C}\right)\end{array}$ & 153.86 & 171.35 & 166.45 & 155.54 \\
\hline $\begin{array}{c}\text { Critical pressure } \\
(\mathrm{MPa})\end{array}$ & 3.65 & 2.90 & 3.62 & 3.34 \\
\hline $\begin{array}{c}\text { Normal boiling } \\
\text { point }(\mathrm{NBP})\left({ }^{\circ} \mathrm{C}\right)\end{array}$ & 15.05 & 33.45 & 18.26 & 14.62 \\
\hline $\begin{array}{c}\text { Tested thermal } \\
\text { stability }\left({ }^{\circ} \mathrm{C}\right)\end{array}$ & 250 & 250 & 175 & 175 \\
\hline $\begin{array}{c}\text { Suction density } \\
\left(\mathrm{kg} \cdot \mathrm{m}^{-3}\right)\end{array}$ & 25.45 & 16.02 & 20.73 & 27.11 \\
\hline $\begin{array}{c}\text { ODP }(\mathrm{CFC}-11=1) \\
{[31]}\end{array}$ & 0 & 0 & 0.00034 & 0.00012 \\
\hline GWP ${ }_{100-\text { years }[31]}$ & 858 & 2 & 1 & $\mathrm{~A} 1$ \\
\hline $\begin{array}{c}\text { ASHRAE Std. 34 } \\
\text { safety class [31] }\end{array}$ & $\mathrm{B} 1$ & $\mathrm{~A} 1$ & & $<1$ \\
\hline
\end{tabular}

${ }^{a}$ At condensing temperature of $60{ }^{\circ} \mathrm{C}$

The theoretical evaluation of the alternative low-GWP refrigerants is based on the corrected compressor efficiencies obtained from Eqs. (25) and (26). These equations consider the difference in thermodynamic properties between the reference refrigerant HFC-245fa and the alternatives.

$$
\begin{gathered}
\eta_{\text {is,low } G W P}=\frac{\left[\left(\frac{P_{2}}{P_{1}}\right)^{\left(\frac{\gamma-1}{\gamma}\right)}\right]_{\text {low } G W P}}{\left[\left(\frac{P_{2}}{P_{1}}\right)^{\left(\frac{\gamma-1}{\gamma}\right)}\right]_{H F C-245 f a}} \cdot \eta_{i s, H F C-245 f a} \\
\eta_{\text {vol,low } G W P}=1-\frac{\left[\left(\frac{P_{2}}{P_{1}}\right)^{\left(\frac{1}{\gamma}\right)}\right]_{l o w G W P}}{\left[\left(\frac{P_{2}}{P_{1}}\right)^{\left(\frac{1}{\gamma}\right)}\right]_{H F C-245 f a}}\left(1-\eta_{v o l, H F C-245 f a}\right)
\end{gathered}
$$

The corrected compressor efficiencies for each refrigerant enables the theoretical evaluation of each candidate based on the HFC-245fa experimental results. The same evaporating and condensing temperatures of HFC-245fa presented in Section 4.1.4 were considered, and the electromechanical efficiency $\left(\eta_{e m}\right)$ is assumed to be constant. The subcooling and superheating degrees are assumed equal for each refrigerant. Fig. 17 shows the isentropic and volumetric corrected efficiencies of the low-GWP refrigerant alternatives. The experimental results of HFC- 
$245 \mathrm{fa}$ illustrate that the compressor isentropic efficiency tends to increase with increasing pressure ratio until the maximum pressure ratio between 3.4 and 4 is achieved, after which the isentropic efficiency decreases. Similarly, the compressor volumetric efficiency increases until the maximum value is achieved, which is higher than that of the isentropic efficiency, after which the compressor volumetric efficiency decreases slowly. Both isentropic and volumetric efficiencies present reasonable values for this application technology.

The alternative low-GWP refrigerants have trends similar to the reference working fluid HFC245fa. While HCFO-1224yd(Z) and HCFO-1233zd(E) have similar behaviour to HFC-245fa in both efficiencies, HFO-1336mzz(Z) shows a completely different trend. At lower pressure ratios, all candidates show lower isentropic efficiencies: this reduction is higher for HFO-1336mzz(Z). However, in this condition, HCFO-1224yd(Z) and HCFO-1233zd(E) have higher volumetric efficiency than HFC-245fa, whereas HFO-1336mzz(Z) presents a reduction of this value. For higher pressure ratios, HFO-1336mzz(Z) presents higher isentropic and volumetric efficiencies than HFC-245fa, whereas the other candidates have similar or even lower values of these compressor parameters.

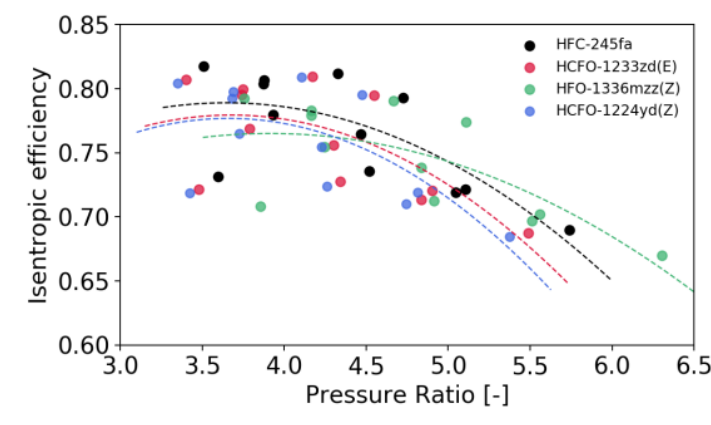

(a)

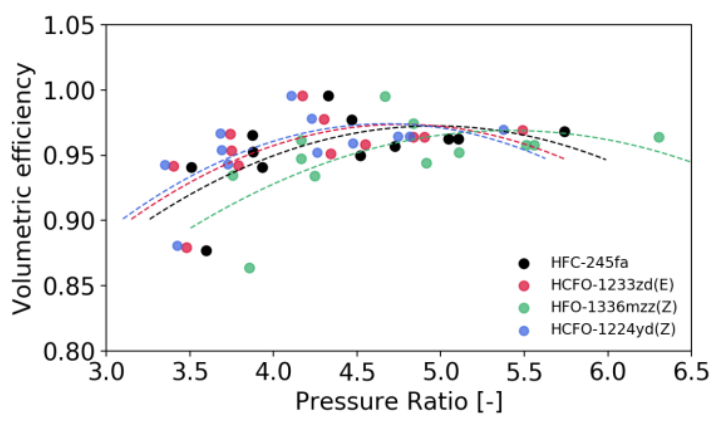

(b)

Fig. 17. Isentropic and volumetric corrected efficiencies of the alternative low-GWP refrigerants

The COP results are shown in Fig. 18, HFC-245fa shows lower COP values than alternative lowGWP refrigerants. While HCFO-1233zd(E) and HCFO-1224zd(Z) have similar trends, HFO$1336 \mathrm{mzz}(\mathrm{Z})$ has the highest COP. This fluid also presents a similar trend to HFC-245fa.

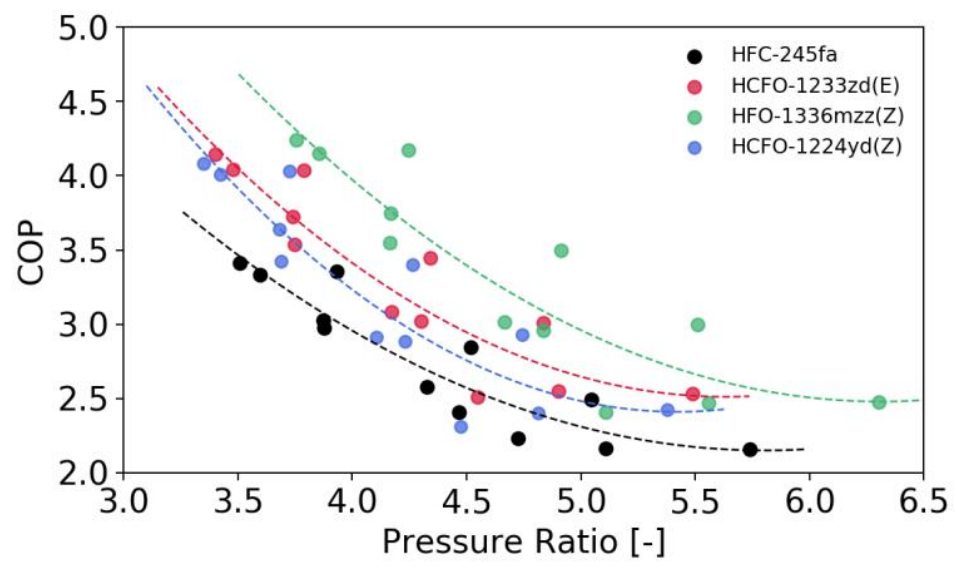

Fig. 18. Estimated COP versus pressure ratio for alternative low-GWP refrigerants.

Although HFO-1336mzz(Z) presents the highest COP, it presents the lowest heating capacity for the same compressor volume swept, as shown in Fig. 19. Hence, it requires a larger compressor than the other alternatives, which exhibit heating capacities similar to that of HFC-245fa. These results are in concordance with the conclusions achieved by Mateu-Royo et al. [32] for the thermodynamic analysis of HCFO and HFO compared to HFC-245fa. Therefore, in the case of a 
retrofit, the selected HCFOs would offer a good alternative and hence they will be considered in future experimental tests with the prototype.

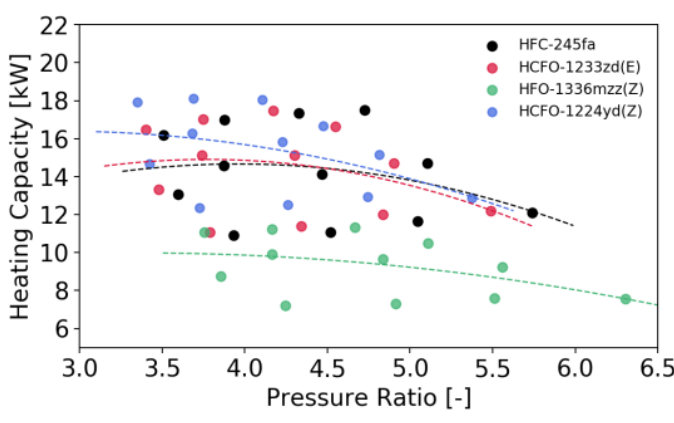

(a)

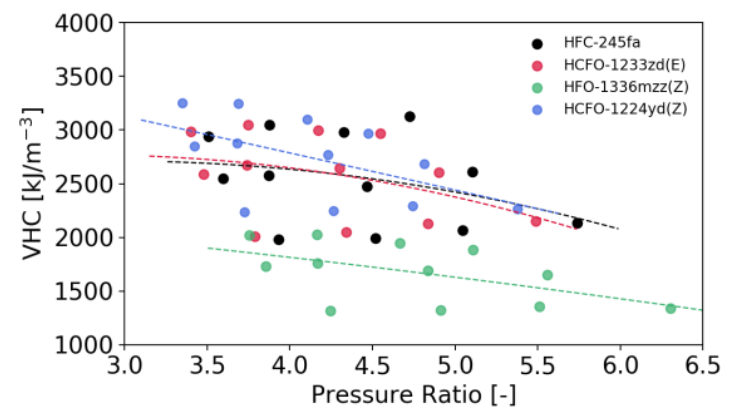

(b)

Fig. 19. Estimated performance parameters for alternative low-GWP refrigerants: a) Heating capacity and b) volumetric heating capacity (VHC)

Additionally, the basic cycle (without IHX) is also simulated to consider the theoretical influence of IHX in each refrigerant and provide valuable knowledge in future experimental tests. The experimental results of HFC-245fa with IHX is used as a reference to present the results calculated as the relative difference. The refrigerant that mostly benefited by the IHX is the HFO$1336 \mathrm{mzz}(\mathrm{Z})$, followed by HCFO-1224yd(Z) and HFC-245fa, as shown in Fig. 20. The first observation can be justified attending to that mentioned by Mateu-Royo et al. [11], who mentions that the refrigerant with the highest IHX benefit is the one that performs worse in the basic cycle. Then, the similarity between the traditional refrigerant HFC-245fa and the alternative low-GWP refrigerants can be explained attending to the similar thermophysical properties of both fluids, highlighted in Mateu-Royo et al. [32].

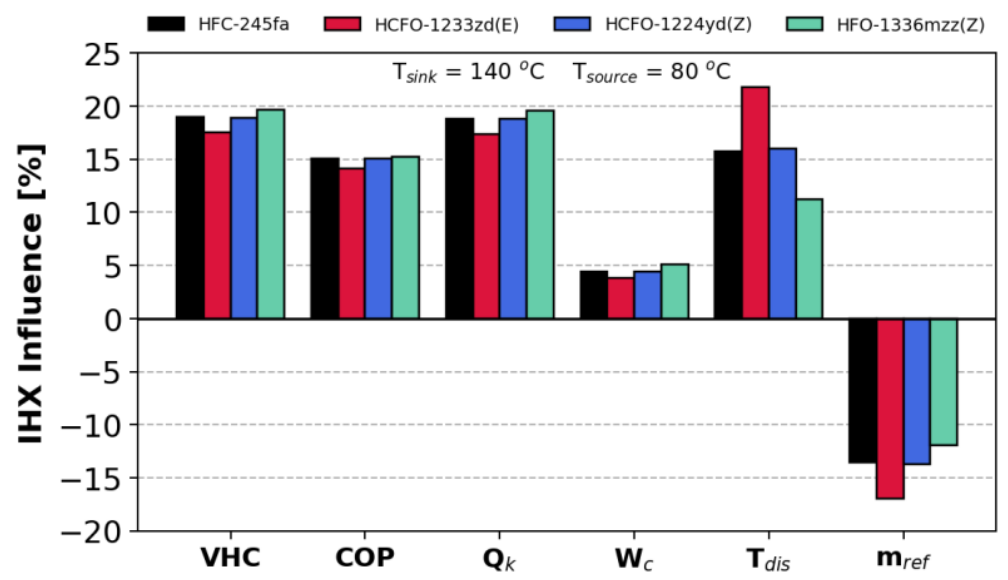

Fig. 20. Estimated IHX influence in each refrigerant for different operating and performance parameters.

\subsection{Environmental evaluation of HTHP integration as a waste heat recovery system}

In addition to the primary energy consumption, the equivalent $\mathrm{CO}_{2}$ emissions represent another useful indicator for policymakers when comparing different heating technologies. As the HTHP prototype is designed to substitute fossil fuel burners in industrial processes, this section compares it with a conventional natural gas-powered burner in terms of $\mathrm{CO}_{2}$ equivalent emissions.

CHP systems tend to improve the overall system efficiency as they produce electricity along with the heat recovered from the exhausts gases [33]. Hence, CHP systems improve the usage of primary energy, and therefore, the European Directive 2012/27/EU [34] encourage European 
countries to use these systems in order to reduce greenhouses gasses emissions. Nevertheless, CHP requires cooling systems to control the temperature inside the combustion chamber. Although both heat gained by combustion air cooling and heat extracted from jacket cooling water could be used directly for building heating (offices or industrial building) along with the production of domestic hot water, the outlet temperatures of this cooling engine system are between $70-100{ }^{\circ} \mathrm{C}[35]$ and therefore cannot be used for electricity or steam production useful for the industry. Hence, the low-grade heat extracted from jacket cooling water of the engine, which represents up to $30 \%$ of the total energy input in the system [35], is rejected to the ambient as waste heat, as shown in Fig. 21.

This low-grade waste heat can be recovered and upgraded using an HTHP system [36]. HTHP can absorb the low-grade waste heat from the cooling engine system and upgrade it up to $140{ }^{\circ} \mathrm{C}$ in order to produce steam or pressurized water useful again for the industrial processes. Consequently, the primary energy of the system along with the total equivalent $\mathrm{CO}_{2}$ emissions is reduced, improving the performance efficiency of the overall system and decarbonizing the industrial sector. A schematic representation of the integration of HTHP as waste heat system is presented in Fig. 21.

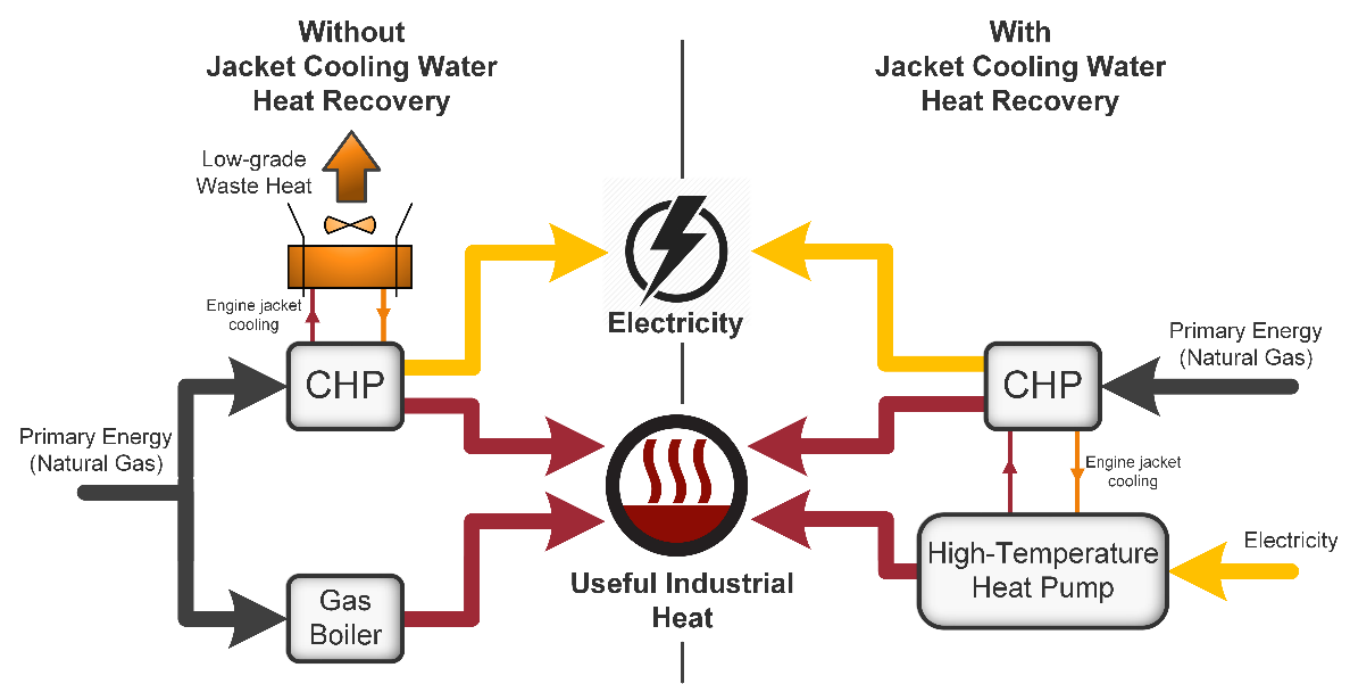

Fig. 21. Integration of HTHP as low-grade waste heat recovery system in CHP installations.

The Total Equivalent Warming Impact (TEWI) indicator has been calculated to quantify the equivalent $\mathrm{CO}_{2}$ emission due to the accidental losses of refrigerant (direct emissions) and to the energy consumption of the HTHP system (indirect emissions). It gives an appropriate approximation to the real environmental impact of vapour compression systems. TEWI method is based on Eq. (27) [37,38].

$$
T E W I=G W P \cdot L \cdot n+G W P \cdot m_{r} \cdot(1-\alpha)+n \cdot E_{a} \cdot \beta
$$

The constant evaporation temperature of $80^{\circ} \mathrm{C}$ and four different condensing temperatures, 110 , 120,130 and $140^{\circ} \mathrm{C}$, have been analysed. Also, this method requires some necessary assumptions depending on the application. The HTHP evaporator exchanges waste heat, based on the experimental data, during 7884 hours per year (90\% of the time). The lifespan of the system $(n)$ is 15 years. The IPCC recommended an annual leakage rate for indirect refrigeration systems contained in machinery rooms of $5 \%$ of the total refrigerant charge $(20 \mathrm{~kg})$ [39]. Nevertheless, in other to have an overview of the sensitivity of the refrigerant leak, 5, 10 and $15 \%$ of the total refrigerant charge are considered as annual leakage rate for HTHP systems. The recycling factor of the refrigerant $(\alpha)$ is omitted for this comparison. 
The calculations have been performed at the UE level and the indirect emission factor $(\beta)$ value is taken from the one proposed for the European Union by the European Environment Agency, $275.9 \mathrm{~g} \mathrm{CO}_{2} \mathrm{kWh}^{-1}$ [40]. For what concerns the natural gas boiler, the efficiency varies between 0.87 and 0.83 for heat sink temperatures between 110 and $140{ }^{\circ} \mathrm{C}$ (respectively) [41] and a emissions factor of $205 \mathrm{~g} \mathrm{CO}_{2} \mathrm{kWh}^{-1}$ has been used [42].

The resulting $\mathrm{CO}_{2}$ equivalent emissions reduction of both systems are shown in Fig. 22. The environmental results show that HTHP system could reduce the equivalent $\mathrm{CO}_{2}$ emission up to $57.3 \%$ compared to conventional heating technology, in this case, a natural gas boiler. Moreover, the refrigerant leak in HTHP system using HFC-245fa could have a slight influence on the total emissions. However, it could be concluded also that the use of the previously mentioned lowGWP refrigerants, with lower values of GWP and higher energy performance than HFC-245fa, could lead to higher reductions of the equivalent $\mathrm{CO}_{2}$ emissions.

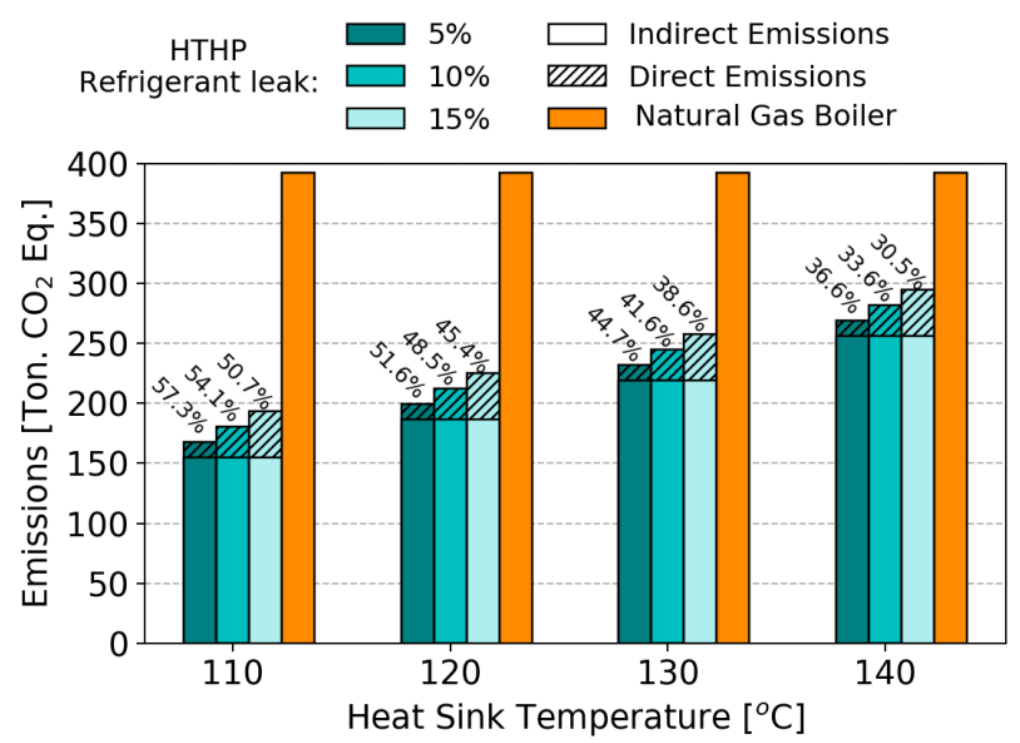

Fig. 22. Equivalent $\mathrm{CO}_{2}$ emission reduction and values of HTHP as recovery system compared to conventional heating technology, natural gas boiler.

\section{Conclusions}

In this paper, we presented the first results of a novel HTHP based on a scroll compressor with an IHX for low-grade waste heat recovery. The focus was on the analysis of the different system parameters to provide guidelines for further design improvement and development. To this end, a twofold approach was followed:

1. System parameters, such as COP and the heating capacity, were determined for a wide range of heat sink and heat source temperatures in order to provide a comprehensive energy evaluation of the HTHP prototype. Moreover, an experimental exergy analysis was realised to determine the components of the system with the highest improvement potential through the exergy evaluation of each vapour compression component.

2. The estimated performance behaviour of the low-GWP refrigerants considered, namely HCFO-1224yd(Z), HCFO-1233zd(E), and HFO-1336mzz(Z), were estimated based on a semi-empirical computational study to provide guidelines for further design advancements and development of HTHPs for low-grade waste heat recovery. Finally, an environmental evaluation of HTHP integration as a waste heat recovery system in CHP installations was presented to illustrate its potential in the decarbonisation of the energyintensive industry sector. 
The following conclusions can be drawn from the results of this study:

- The novel HTHP system with scroll compressor provides significant performance improvements for low-grade waste heat recovery. At heat source temperature of $80{ }^{\circ} \mathrm{C}$ and heat sink temperature of $140{ }^{\circ} \mathrm{C}$, the $\mathrm{COP}$ was 2.23 . The highest $\mathrm{COP}$ was 3.41 , achieved at heat source and sink temperatures of 80 and $110{ }^{\circ} \mathrm{C}$, respectively.

- The energy analysis showed that the heating capacity is highly influenced by the heat source temperature, while the COP is significantly affected by the heat sink temperature. Thus, further designs with variable heat source and sink temperatures will require a detailed analysis of both performance parameters.

- The exergy analysis illustrated the areas of potential performance improvements. The compressor is the cycle component with the highest irreversibility and therefore, has the highest margin of improvement. Mechanical design and lubrication improvements in this component could increase the overall system efficiency. The expansion valve are the component with the second highest irreversibility of the system. Its replacement with ejector could improve the performance of the installation.

- The semi-empirical computational evaluation showed that either HCFO-1233zd(E) or HCFO-1224yd(Z) could be used a possible drop-in replacements for HFC-245fa in hightemperature heat pumps. Although HFO-1336mzz(Z) presents higher COP that the other refrigerants, it requires a greater compressor size to provide similar heating capacities owing to its lower suction density.

- The potential of HTHP as waste heat recovery systems was demonstrated with the integration of this technology in a CHP installation. The environmental results showed that the HTHP system could reduce the equivalent $\mathrm{CO}_{2}$ emission up to $57.3 \%$ compared to conventional heating technologies, in this case, a natural gas boiler.

\section{Acknowledgements}

The authors acknowledge the Spanish Government for the financial support under projects RTC2017-6511-3 and Adrián Mota-Babiloni through the postdoctoral grant FJCI-2016-28324. Furthermore, the authors acknowledge the Universitat Jaume I (Castelló de la Plana, Spain) for the financial support under the projects UJI-B2018-24 and Carlos Mateu-Royo for the funding received through the $\mathrm{PhD}$ grant PREDOC/2017/41. Finally, the authors acknowledge the Regional Government for the financial support under grant FEDEGENT/2018/002.

\section{References}

[1] Wesseling JH, Lechtenböhmer S, Åhman M, Nilsson LJ, Worrell E, Coenen L. The transition of energy intensive processing industries towards deep decarbonization: Characteristics and implications for future research. Renew Sustain Energy Rev 2017;79:1303-13. doi:10.1016/J.RSER.2017.05.156.

[2] Bataille C, Åhman M, Neuhoff K, Nilsson LJ, Fischedick M, Lechtenböhmer S, et al. A review of technology and policy deep decarbonization pathway options for making energy-intensive industry production consistent with the Paris Agreement. J Clean Prod 2018;187:960-73. doi:10.1016/J.JCLEPRO.2018.03.107.

[3] Meyers S, Schmitt B, Vajen K. The future of low carbon industrial process heat: A comparison between solar thermal and heat pumps. Sol Energy 2018;173:893-904. doi:10.1016/J.SOLENER.2018.08.011. 
[4] IPCC. Climate Change 2014: Synthesis Report. Contribution of Working Groups I, II and III to the Fifth Assessment Report of the Intergovernmental Panel on Climate Change [Core Writing Team, R.K. Pachauri and L.A. Meyer (eds.)]. Geneva, Switzerland, 2014.

[5] Forman C, Muritala IK, Pardemann R, Meyer B. Estimating the global waste heat potential. Renew Sustain Energy Rev 2016;57:1568-79. doi:10.1016/j.rser.2015.12.192.

[6] Seck GS, Guerassimoff G, Maïzi N. Heat recovery using heat pumps in non-energy intensive industry: Are Energy Saving Certificates a solution for the food and drink industry in France? Appl Energy 2015;156:374-89. doi:10.1016/j.apenergy.2015.07.048.

[7] Brückner S, Liu S, Miró L, Radspieler M, Cabeza LF, Lävemann E. Industrial waste heat recovery technologies: An economic analysis of heat transformation technologies. Appl Energy 2015;151:157-67. doi:10.1016/j.apenergy.2015.01.147.

[8] Arpagaus C, Bless F, Uhlmann M, Schiffmann J, Bertsch SS. High temperature heat pumps: Market overview, state of the art, research status, refrigerants, and application potentials. Energy 2018;152:985-1010. doi:10.1016/J.ENERGY.2018.03.166.

[9] Wang JF, Brown C, Cleland DJ. Heat pump heat recovery options for food industry dryers. Int J Refrig 2018;86:48-55. doi:10.1016/J.IJREFRIG.2017.11.028.

[10] Bamigbetan O, Eikevik TM, Nekså P, Bantle M. Review of vapour compression heat pumps for high temperature heating using natural working fluids. Int J Refrig 2017;80:197-211. doi:10.1016/j.ijrefrig.2017.04.021.

[11] Mateu-Royo C, Navarro-Esbrí J, Mota-Babiloni A, Amat-Albuixech M, Molés F. Theoretical evaluation of different high-temperature heat pump configurations for lowgrade waste heat recovery. Int J Refrig 2018. doi:10.1016/j.ijrefrig.2018.04.017.

[12] Cao X-Q, Yang W-W, Zhou F, He Y-L. Performance analysis of different hightemperature heat pump systems for low-grade waste heat recovery. Appl Therm Eng 2014;71:291-300. doi:10.1016/j.applthermaleng.2014.06.049.

[13] Mota-Babiloni A, Mateu-Royo C, Navarro-Esbrí J, Molés F, Amat-Albuixech M, Barragán-Cervera Á. Optimisation of high-temperature heat pump cascades with internal heat exchangers using refrigerants with low global warming potential. Energy 2018;165:1248-58. doi:10.1016/j.energy.2018.09.188.

[14] Yang W wei, Cao X qi, He Y ling, Yan F yu. Theoretical study of a high-temperature heat pump system composed of a CO2 transcritical heat pump cycle and a R152a subcritical heat pump cycle. Appl Therm Eng 2017;120:228-38. doi:10.1016/j.applthermaleng.2017.03.098.

[15] Liu Z, Zhao L, Zhao X, Li H. The occurrence of pinch point and its effects on the performance of high temperature heat pump. Appl Energy 2012;97:869-75. doi:10.1016/j.apenergy.2011.12.061.

[16] Zühlsdorf B, Jensen JK, Cignitti S, Madsen C, Elmegaard B. Analysis of temperature glide matching of heat pumps with zeotropic working fluid mixtures for different temperature glides. Energy 2018;153:650-60. doi:10.1016/J.ENERGY.2018.04.048.

[17] Bamigbetan O, Eikevik TM, Nekså P, Bantle M, Schlemminger C. Experimental investigation of a prototype R-600 compressor for high temperature heat pump. Energy 
[18] Chamoun M, Rulliere R, Haberschill P, Peureux J-L. Experimental and numerical investigations of a new high temperature heat pump for industrial heat recovery using water as refrigerant. Int J Refrig 2014;44:177-88. doi:10.1016/j.ijrefrig.2014.04.019.

[19] Bobelin D, Bourig A, Peureux J. Experimental results of a newly developed very high temperature industrial heat pump $\left(140^{\circ} \mathrm{C}\right)$ equipped with scroll compressors and working with a new blend refrigerant. Int Refrig Air Cond Conf 2012.

[20] Meroni A, Zühlsdorf B, Elmegaard B, Haglind F. Design of centrifugal compressors for heat pump systems. Appl Energy 2018;232:139-56.

doi:10.1016/J.APENERGY.2018.09.210.

[21] Ma X, Zhang Y, Fang L, Yu X, Li X, Sheng Y, et al. Performance analysis of a cascade high temperature heat pump using R245fa and BY-3 as working fluid. Appl Therm Eng 2018;140:466-75. doi:10.1016/J.APPLTHERMALENG.2018.05.052.

[22] Zhang Y, Zhang Y, Yu X, Guo J, Deng N, Dong S, et al. Analysis of a high temperature heat pump using BY-5 as refrigerant. Appl Therm Eng 2017;127:1461-8. doi:10.1016/J.APPLTHERMALENG.2017.08.072.

[23] Yu X, Zhang Y, Kong L, Zhang Y. Thermodynamic analysis and parameter estimation of a high-temperature industrial heat pump using a new binary mixture. Appl Therm Eng 2018;131:715-23. doi:10.1016/j.applthermaleng.2017.12.039.

[24] Deng N, Jing X, Cai R, Gao J, Shen C, Zhang Y, et al. Molecular simulation and experimental investigation for thermodynamic properties of new refrigerant NBY-1 for high temperature heat pump. Energy Convers Manag 2019;179:339-48.

doi:10.1016/J.ENCONMAN.2018.10.076.

[25] Arpagaus C, Bless F, Uhlmann M, Büchel E, Frei S, Schiffmann J, et al. High temperature heat pump using HFO and HCFO refrigerants - System design , simulation, and first experimental results. 17th Int Refrig Air Cond Conf Purdue, July 9-12, 2018 2018:1-10.

[26] Lemmon EW, Bell IH, Huber ML, McLinden MO. NIST Standard Reference Database: Reference Fluid Thermodynamic and Transport Properties-REFPROP, Version 10. Natl Inst Stand Technol Stand Ref Data Program, Boulder, CO 2018.

[27] Taylor BN, Kuyatt CE. Guidelines for Evaluating and Expressing the Uncertainty of NIST Measurement Results. Natl Inst Stand Technol 1994.

[28] Klein S. Engineering Equation Solver (EES) V10.2. Fchart Software, Madison, USA WwwFchartCom 2006.

[29] Dincer I, Rosen MA. Exergy: Energy, Environment and Sustainable Development (2nd Edition). Elsevier 2013.

[30] Hasan AA, Goswami DY, Vijayaraghavan S. First and second law analysis of a new power and refrigeration thermodynamic cycle using a solar heat source. Sol Energy 2002;73:385-93. doi:10.1016/S0038-092X(02)00113-5.

[31] ASHRAE. ASHRAE Handbook Fundamentals. Am Soc Heating, Refrig AirConditioning Eng 2017. 
[32] Mateu-Royo C, Navarro-Esbrí J, Mota-Babiloni A, Amat-Albuixech M, Molés F. Thermodynamic analysis of low GWP alternatives to HFC-245fa in high-temperature heat pumps: HCFO-1224yd(Z), HCFO-1233zd(E) and HFO-1336mzz(Z). Appl Therm Eng 2019. doi:10.1016/j.applthermaleng.2019.02.047.

[33] Martinez S, Michaux G, Salagnac P, Bouvier J-L. Micro-combined heat and power systems (micro-CHP) based on renewable energy sources. Energy Convers Manag 2017;154:262-85. doi:10.1016/J.ENCONMAN.2017.10.035.

[34] Directive 2012/27/EU of the European Parliament and of the Council of 25 October 2012 on energy efficiency, amending Directives 2009/125/EC and 2010/30/EU and repealing Directives 2004/8/EC and 2006/32/EC 2012.

[35] Hoang AT. Waste heat recovery from diesel engines based on Organic Rankine Cycle. Appl Energy 2018;231:138-66. doi:10.1016/J.APENERGY.2018.09.022.

[36] Urbanucci L, Bruno JC, Testi D. Thermodynamic and economic analysis of the integration of high-temperature heat pumps in trigeneration systems. Appl Energy 2019;238:516-33. doi:10.1016/J.APENERGY.2019.01.115.

[37] Makhnatch P, Khodabandeh R. The role of environmental metrics (GWP, TEWI, LCCP) in the selection of low GWP refrigerant. Energy Procedia 2014;61:2460-3. doi:10.1016/j.egypro.2014.12.023.

[38] AIRAH. Methods of calculating Total Equivalent Warming Impact (TEWI). Best Pract Guidel Aust Inst Refrig Air Cond Heat 2012.

[39] IPCC. IPCC/TEAP special report on safeguarding the ozone layer and the global climate system: Issues related to hydrofluorocarbons and perfluorocarbons. Cambridge Publ Intergov Panel Clim Chang [by] Cambridge Univ Press 2005.

[40] EEA. Overview of electricity production and use in Europe. Eur Enviroment Agency 2016.

[41] Baldi S, Quang T Le, Holub O, Endel P. Real-time monitoring energy efficiency and performance degradation of condensing boilers. Energy Convers Manag 2017;136:32939. doi:10.1016/J.ENCONMAN.2017.01.016.

[42] Scoccia R, Toppi T, Aprile M, Motta M. Absorption and compression heat pump systems for space heating and DHW in European buildings: Energy, environmental and economic analysis. J Build Eng 2018;16:94-105. doi:10.1016/J.JOBE.2017.12.006. 